\title{
Prioritization Framework for Advanced Systems of Urban Roads in the Context of Smart Cities
}

Jinwoong Lee

West Virginia University, j10190@mix.wvu.edu

Follow this and additional works at: https://researchrepository.wvu.edu/etd

Part of the Civil Engineering Commons

\section{Recommended Citation}

Lee, Jinwoong, "Prioritization Framework for Advanced Systems of Urban Roads in the Context of Smart Cities" (2021). Graduate Theses, Dissertations, and Problem Reports. 8259.

https://researchrepository.wvu.edu/etd/8259

This Thesis is protected by copyright and/or related rights. It has been brought to you by the The Research Repository @ WVU with permission from the rights-holder(s). You are free to use this Thesis in any way that is permitted by the copyright and related rights legislation that applies to your use. For other uses you must obtain permission from the rights-holder(s) directly, unless additional rights are indicated by a Creative Commons license in the record and/ or on the work itself. This Thesis has been accepted for inclusion in WVU Graduate Theses, Dissertations, and Problem Reports collection by an authorized administrator of The Research Repository @ WVU. For more information, please contact researchrepository@mail.wvu.edu. 


\title{
Prioritization Framework for Advanced Systems of Urban Roads in the Context of Smart
} Cities

\section{Jinwoong Lee}

\author{
A THESIS \\ Submitted to the Benjamin M. Statler College of Engineering and Mineral Resources \\ at West Virginia University \\ in partial fulfillment of the requirements for the degree of \\ Master of Science \\ in \\ Civil and Environmental Engineering \\ Yoojung Yoon, Ph.D., Chair \\ Fei Dai, Ph.D. \\ Kakan Dey, Ph.D. \\ Department of Civil and Environmental Engineering \\ Morgantown, West Virginia \\ 2021
}

Keywords: Smart city, Indicator, Urban road, Intelligent urban infrastructure,

Framework, Prioritization, Text mining, Road system

Copyright 2021 Jinwoong Lee 


\section{ABSTRACT \\ Prioritization Framework for Advanced Systems of Urban Roads in the Context of Smart Cities}

\section{Jinwoong Lee}

The concept of a smart city has emerged as a solution to resolve various urban challenges by applying advanced systems for the functions of the city (e.g., environment, economy, infrastructure, governance, and people). Urban infrastructure with the use of modern technologies, such as Information Communication Technology and the Internet of Things, plays an essential role in enhancing the capability of the city to resolve the challenges. Particularly, urban roads supported by advanced systems with modern technologies serve as a principal bedrock to establish a smart city. Witnessing the benefits from intelligent urban roads has promoted city stakeholders to make investment decisions in innovating their road facilities (i.e., roadway and roadside facilities) with advanced systems. The investment decisions to be efficient start from understanding the current development status of urban roads to identify the needs for advanced systems. Therefore, the objective of this thesis was to present a framework to prioritize advanced systems identified by assessing the current development status of urban roads for innovation. The current development status assessment can be done using the hierarchy table of indicators and measures developed by this thesis. As a hierarchy table organizes various elements in parent-child relationships, the hierarchy table developed consists of three levels: smart city components, indicators, and measures. The smart city components are the result of a synthesis study that reviewed various smart city indexes. The keyword network analysis, one of the text mining techniques, was used to develop the indicators and measures. The measures at the lowest hierarch level are considered to identify advanced systems that enhance the current development status of urban roads. The prioritization framework uses the cost-effectiveness values of advanced systems that are combined by the weights at the component and indicator levels. The effectiveness values of advanced systems need a normalization because they are in different scales and units in general. The process of the presented prioritization framework was demonstrated by employing a hypothetical 
example. The contributions of this thesis include: 1) the development of the hierarchy table of indicators and measures that can dedicate to evaluating the current development status of urban roads and identifying advanced systems for urban road innovation, and 2) the hierarchy table development process can be applied to developing indicators and measures focusing other individual service areas. 3) The advanced system prioritization framework can increase efficiency in investing city-wide resources in highly needed and valuable advanced systems, and 4) be applied to any type of urban infrastructure due to the practicality of the weight estimation method. 


\section{ACKNOWLEDGEMENTS}

First, I would like to thank Dr. Yoojung Yoon, Dr. Fei Dai, and Dr. Kakan Dey for serving on this graduate committee. Thanks to Dr. Yoon's guidance, I was able to gain a profound understanding of the research and achieve the research quality. He also gave me much guidance and encouragement regarding my future as an advisor during the pursuit of this master's degree. Dr. Dai and Dr. Dey helped me broaden my knowledge of civil engineering through high-quality classes. Particularly, Dr. Dey's intelligent transportation system class was really helpful for conducting this thesis. Lastly, I also would like to thank all the Wadsworth Department of Civil and Environmental Engineering faculties and staff for their kindness.

Next, I would like to thank my friends, John Garlow, Mohhammad Sujon, and Shirin Hassan. They helped me adjust well to West Virginia University. We were able to share many thoughts and knowledge while taking classes together, and the break time with them was a happy memory for me. I would also like to thank my Korean friends who gave me many good memories. They helped me enjoy life in Morgantown and had much experience in America. Lastly, I would like to express my gratitude to my most precious family. My mother's and father's pray and my sister's bits of advice were helpful for living in America. Thank you once again to my mother, father, and older sister, who always care for and support me from behind. 


\section{TABLE OF CONTENTS}

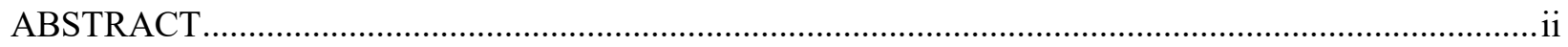

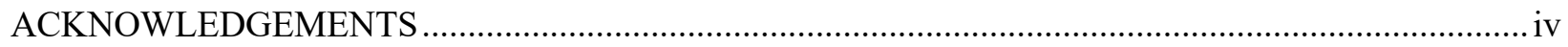

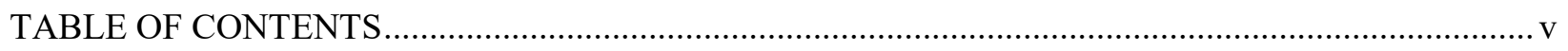

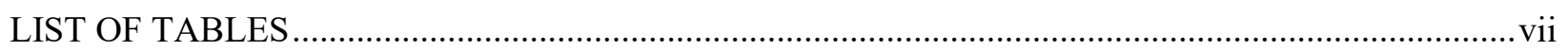

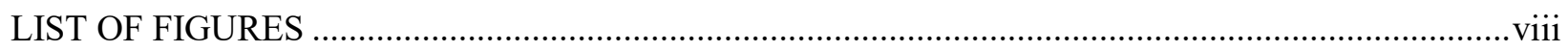

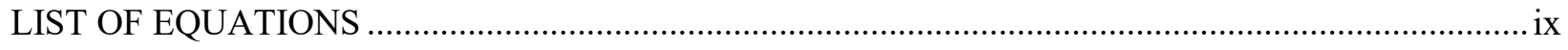

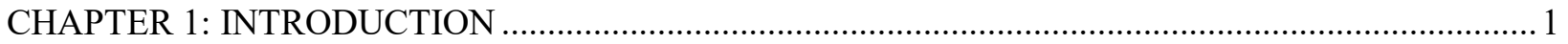

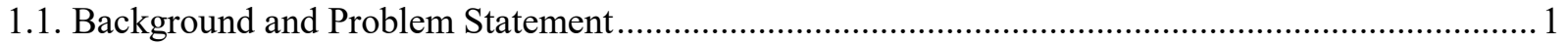

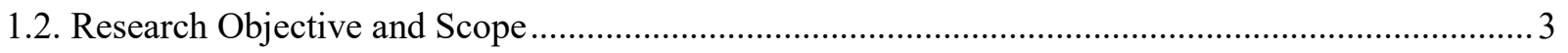

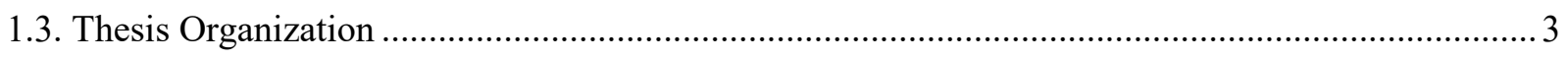

CHAPTER 2: PREVIOUS STUDIES ON SMART CITY CONCEPTS AND SMART CITY INDEXES 4

2.1. Indicators-related Studies for Road Infrastructures …............................................................ 4

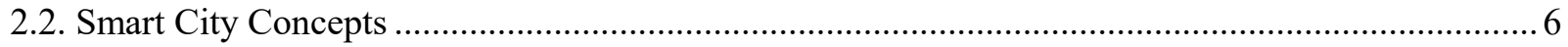

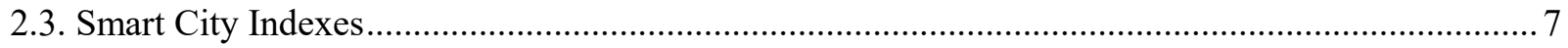

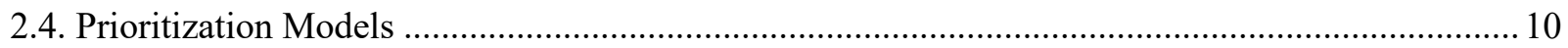

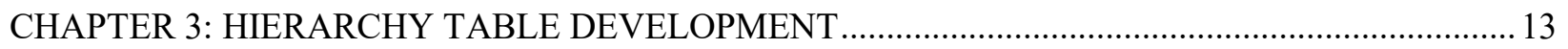

3.1. Procedures to Develop a Hierarchy Table for Urban Roads.................................................... 13

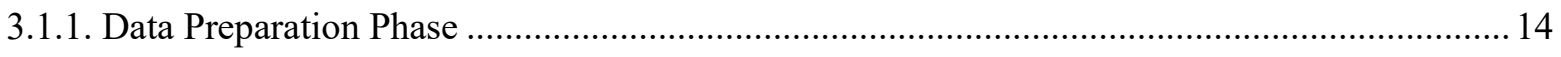

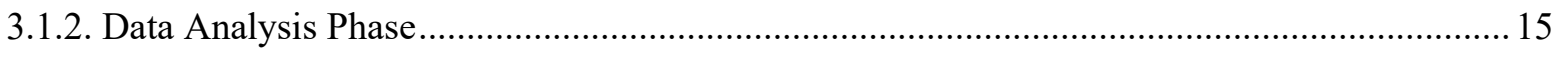

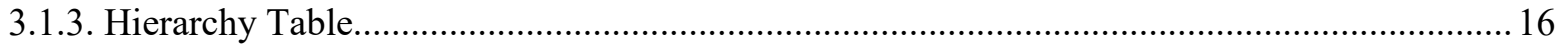

3.2. Development of Indicators and Measures for Hierarchy Table ................................................... 17

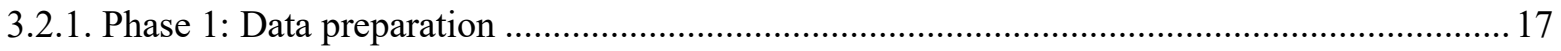

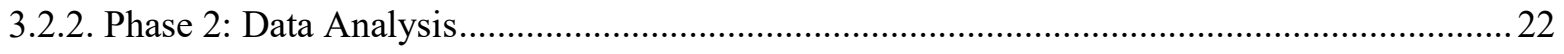

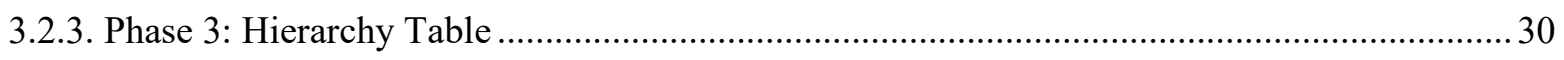

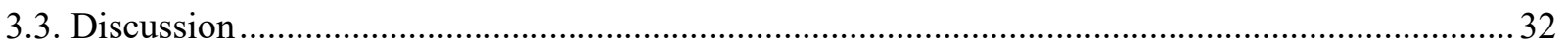

CHAPTER 4: PRIORITIZATION FRAMEWORK FOR ADVANCED SYSTEMS............................. 36

4.1. Framework for Advanced System Priority Application................................................................ 36

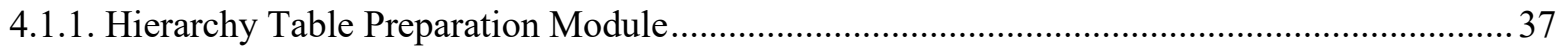

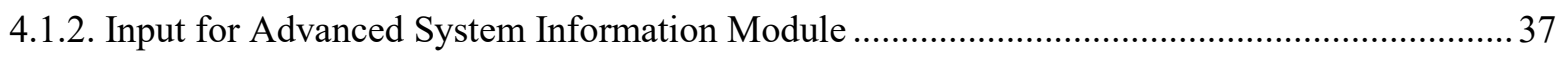

4.1.3. Advanced System Prioritization Module ............................................................................ 39 
4.2. Application of Advanced System Prioritization Framework …................................................ 45

4.2.1. Module-1: Hierarchy Table Preparation ................................................................................. 45

4.2.2. Module-2: Input for Advanced System Information............................................................ 46

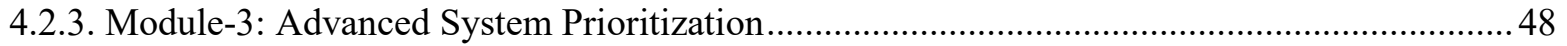

4.2.4. Discussions on the Application Procedures and Result ..........................................................52

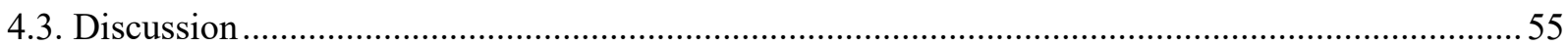

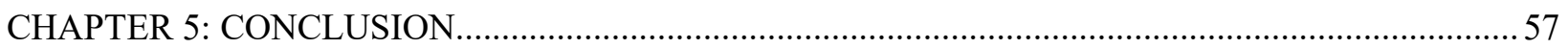

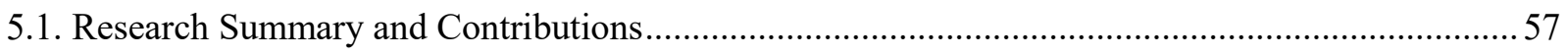

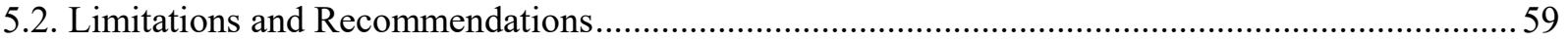

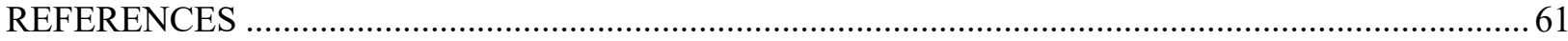




\section{LIST OF TABLES}

Table 2.1. Research on the Indicators for Transportation Systems ........................................................... 5

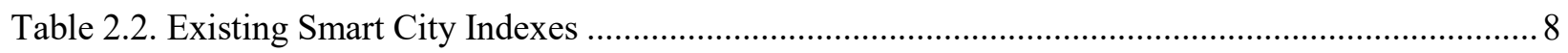

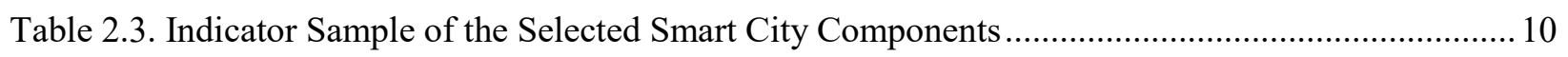

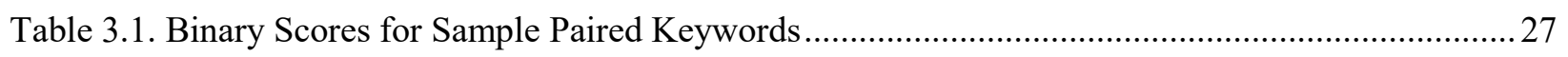

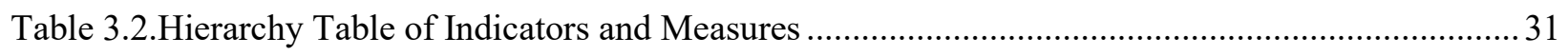

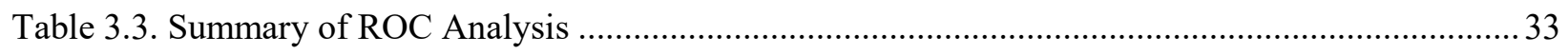

Table 4.1. Example of a Hierarchy Table for Component and Indicator Weights ..................................42

Table 4.2. Example of \%Current Achievement and \%Demand Value Calculations .................................43

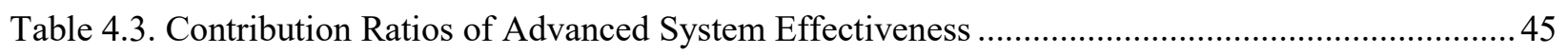

Table 4.4. Example of Advanced Systems Matching to Measures with Cost and Effectiveness ............... 47

Table 4.5. The T, BL, and CDS Values Assumed for each Measure........................................................ 48

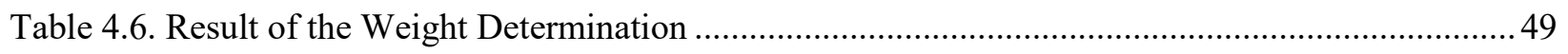

Table 4.7. CE and Weighted CE Results for the Advanced Systems ...................................................51

Table 4.8. Result of Advanced Systems Prioritization ...........................................................................52 


\section{LIST OF FIGURES}

Figure 2.1. A Hierarchical Structure of Smart City Indexes ............................................................. 8

Figure 3.1. Phases for a Hierarchy Table Development ..................................................................... 14

Figure 3.2. Smart City Components retrieved from the Smart City Indexes in ........................................ 19

Figure 3.3. Main Sentences Classified by Smart City Components ......................................................2

Figure 3.4. Example for the Keyword Extraction Process ..................................................................2

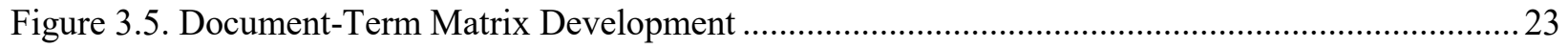

Figure 3.6. Top-ten Keywords for each Smart City Component .........................................................2 25

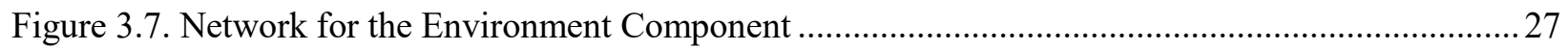

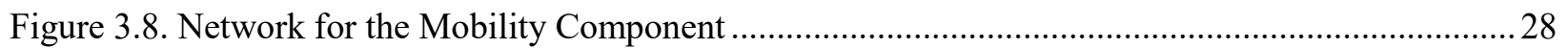

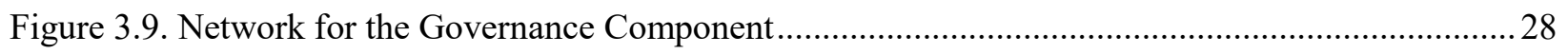

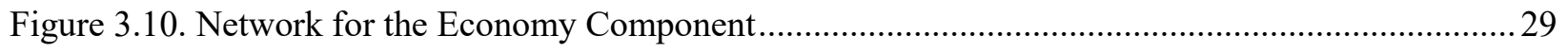

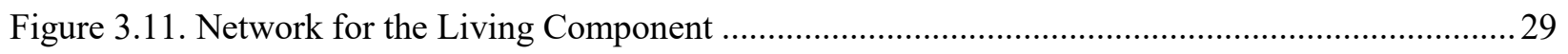

Figure 3.12. Numbers of the Sentences and Cut-off Values ................................................................ 34

Figure 4.1. Framework to Prioritize Advanced Systems …................................................................... 36

Figure 4.2. Possible Scenarios in Case-1: a) all measures on progress, b) scenario 1, c) scenario 2, and d) scenario 3 


\section{LIST OF EQUATIONS}

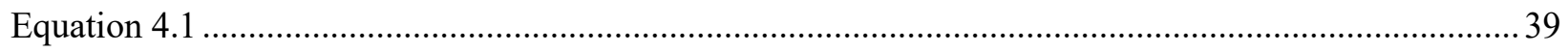

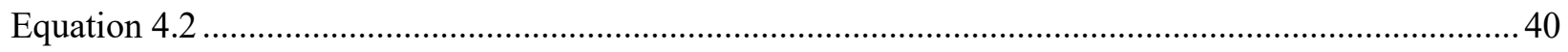

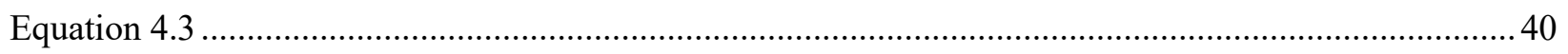

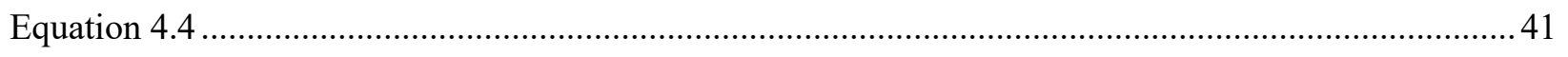

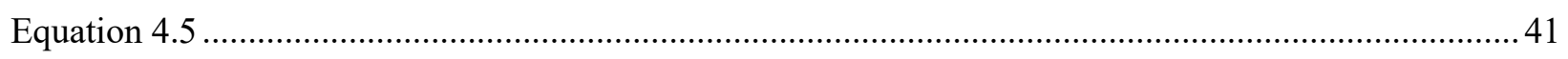

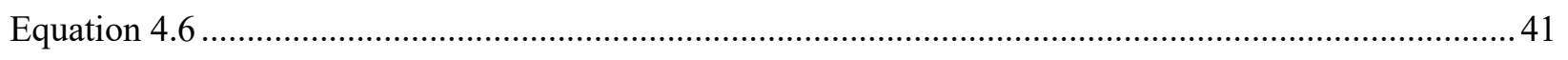

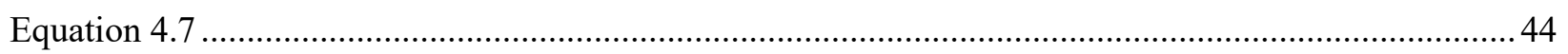

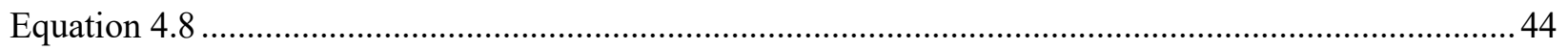

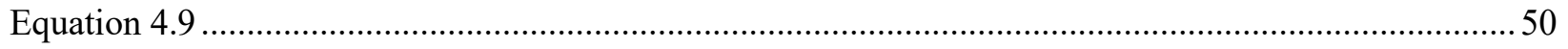

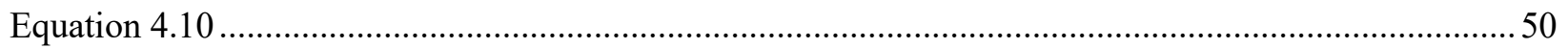

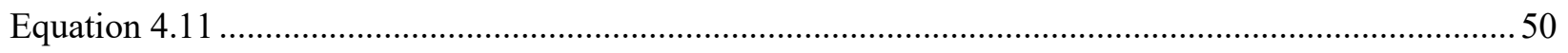




\section{CHAPTER 1: INTRODUCTION}

\subsection{Background and Problem Statement}

A smart city has emerged as a strategy to resolve various problems caused by the dramatic increase in urban populations and improve the quality of citizens' life by applying modern, innovative technologies such as Information and Communications Technology (ICT) and Internet of Things (IoT) (Chourabi et al., 2012). Thus, there have been increasing efforts to transition cities from conventional to smart among city stakeholders by understanding the current development status of their cities so that appropriated investment decisions into modern technologies can be made. A smart city index is a tool to evaluate the smartness of urban cities and monitor the progressive performance of the cities moving toward smart cities over the years (Sharifi, 2019). Various smart city indexes were presented for different evaluation purposes. The organizations and institutes in Europe had led to studying to develop various smart city indexes, such as the Cities in Motion Index (Berrone et al., 2019), Smart City Strategy Index (Roland Berger, 2019), and European Smart City Index (Giffinger et al., 2007). There are also the smart city indexes suggested by a few other groups, such as the Smart Cities Index by the Indian School of Business (Mohan et al., 2017) and the Global Smart Sustainable City Index by the International Telecommunication Union (Smiciklas and Imran, 2018). These smart city indexes commonly use a set of smart city components (e.g., environment, infrastructure, living, economy, and people) and indicators and measures associated with each component for the evaluation process.

A smart city has been expressed by different terms, such as a digital, intelligent, ubiquitous, or sustainable city. (Yovanof and Hazapis, 2009). However, these terms have a common point of view to represent a smart city as a city developed by applying modern, advanced technologies to physical infrastructure (Eremia et al., 2017). Physical infrastructure with the application of modern, innovative technologies can enhance the capability of a city for economic development, social prosperity, and a 
sustainable environment (Vasudavan et al., 2019). Among the various types of physical infrastructure, a transportation network supported by advanced technologies and materials serves as a principal foundation to build a smart city (Li et al., 2015; Agarwal et al., 2015). For example, urban transportation facilities utilizing ICT can help a smart city solve urban problems such as traffic congestion, energy consumption, and public safety (Figueiredo et al., 2001; Menouar et al., 2017; Sumalee and Ho, 2018). Also, the use of novel, advanced paving materials can improve road surface skid resistance so that road accidents can be reduced while enhancing the safety of road users (Lai et al., 2015). In this way, advanced systems, which are the integration of modern, innovative technologies or materials into urban roads, can bring a variety of positive effects to a smart city. For example, advanced systems of urban roads can contribute to a smart city to preserve the environment, enhance traffic mobility, sustain road conditions, improve living quality, and promote economic development (Ziarmand, 2013; Sun et al., 2018).

Witnessing the benefits of advanced systems in an urban transportation network introduced the necessity of developing a strategic investment decision on advanced systems to city officials. In general, a good investment decision for transportation asset management is achieved through the flow of the right information about current needs for the right strategies at the right time (American Association of State Highway and Transportation Officials, 2011). Therefore, efficient, reliable decision-making for investment first requires an understanding of the current development status of urban roads by using an evaluation tool like a smart city index. However, since existing smart city indexes focus on evaluating entire service areas required for a city to be smart, the use of these indexes are not suitable for individual service areas (i.e., urban roads in a smart city) that need more specific customized evaluation. That is, smart city indexes evaluate and monitor cities based on various indicators and measures for the smart city components that encompass all service areas required for the city to be smart. Thus, these indicators and measures are designed to be comprehensive to capture the overall status of city development, which is, however, not relevant for a detailed evaluation of an individual service area. 


\subsection{Research Objective and Scope}

This thesis aims to develop a framework to prioritize advanced systems for urban roads using a hierarchy table of indicators and measures that can assess the current status of urban roads in the context of a smart city. The scope of this thesis focuses on the development of a hierarchy table and prioritization framework for urban roads in a city transitioning into a smart city. The urban roads in this study include roadway facilities, such as roads, bridges, tunnels, and over/underpasses and roadside facilities such as traffic signals and signs, parking facilities, guardrails, streetlights, crosswalks, and sidewalks, within a city boundary. This study makes it clear to define advanced systems as the integration of modern, innovative technologies and materials such as ICT, IoT, sensing technologies, Cloud computing, optical fibers, and piezoelectric device into urban roads (Sun et al., 2018). For example, the automatic street lighting system is an advanced system made by integrating IoT, sensing, or LED technology into streetlights.

\subsection{Thesis Organization}

The remainder of this thesis is structured as follows: Chapter 2 is a comprehensive literature review of the smart city concepts and smart city indexes. Chapter 3 introduces the hierarchy table development through the following steps: 1) data preparation through a discovery search and preprocessing of the data collected, 2) data analysis for keyword frequency analysis and keyword network generation, and 3) hierarchy table development through keyword connotation and indicators development. Chapter 4 presents the advanced system prioritization framework, which consists of three phases: 1) hierarchy table preparation, 2) input for system information on cost and effectiveness, and 3) system prioritization through weight determination and cost-effectiveness estimation. Chapter 5 describes overall conclusions, including the research summary, contribution of this thesis, limitations, and recommendations for future work. 


\section{CHAPTER 2: PREVIOUS STUDIES ON SMART CITY CONCEPTS AND SMART CITY INDEXES}

\subsection{Indicators-related Studies for Road Infrastructures}

Numerous studies have been conducted to develop various indicators for road infrastructures. These indicators can be classified into three categories according to their different purposes (facility maintenance, sustainability, and Intelligent Transportation System (ITS) performance), as shown in Table 2.1. The indicators related to facility maintenance, which were developed many years ago for the management of traditional road infrastructures, focus on the structural and functional conditions of roads by identifying needs such as resilience, winter maintenance, and pavement quality assurance. The purpose of sustainability-related indicators is to evaluate the operational efficiency of transportation networks from the perspective of sustainability by minimizing their environmentally harmful effects on the next generation while fulfilling the needs of future generations (Haghshenas and Vaziri, 2012; Kumar and Anbanandam, 2020). As the innovative advancements in technologies were contributing to the evolution of ITS, some researchers were investigating indicators to measure ITS post-performance for transportation systems. Li et al. (2015) suggested measuring traffic efficiency in a "smart" community, using indicators such as the buffering time index, travel time index, and speed reduction. Kaparias et al. (2011) introduced performance indicators such as traffic efficiency, traffic safety, pollution reduction, social inclusion, and land use for ITS, which then were used to evaluate the operational improvement of transportation systems after the ITS application. These indicators to evaluate the ITS post-application performance of transportation systems are essential for effective feedback. However, as the ITS encompasses entire urban road services, the indicators for ITS are comprehensive to include all ITS targets such as vehicles, users, and infrastructures rather than exclusively road facilities. 
Table 2.1. Research on the Indicators for Transportation Systems

\begin{tabular}{|c|c|c|}
\hline Purpose & Researchers & Summary \\
\hline \multirow{3}{*}{ Facility maintenance } & $\begin{array}{l}\text { Leobons et al. } \\
(2019)\end{array}$ & $\begin{array}{l}\text { Indicators for the evaluation of urban road infrastructure } \\
\text { resilience (e.g., route capacity, accessibility level, travel } \\
\text { time/distance, and etc.) }\end{array}$ \\
\hline & Suggett et al. (2006) & $\begin{array}{l}\text { Development of winter severity indicator models winter road } \\
\text { maintenance (e.g., air temperature, snowfall, and etc.) }\end{array}$ \\
\hline & $\begin{array}{l}\text { Hausman \& Buttlar } \\
(2002)\end{array}$ & $\begin{array}{l}\text { Pavement quality indicator for the density of asphalt } \\
\text { pavement } \\
\text { (e.g., density, moisture, and temperature) }\end{array}$ \\
\hline \multirow{5}{*}{$\begin{array}{l}\text { Sustainability of } \\
\text { transportation system }\end{array}$} & $\begin{array}{l}\text { Chestnut \& Mason } \\
\text { (2019) }\end{array}$ & $\begin{array}{l}\text { Indicators for sustainable transportation focusing on transit, } \\
\text { accessibility, and city characteristics } \\
\text { (e.g., people near rapid transit, access to jobs by sustainable } \\
\text { transport, sustainable transport mode share, and etc.) }\end{array}$ \\
\hline & $\begin{array}{l}\text { Chakhtoura \& } \\
\text { Pojani (2016) }\end{array}$ & $\begin{array}{l}\text { Case study employing indicators to evaluate the } \\
\text { effectiveness of sustainability of urban transport plan (e.g., } \\
\text { public transport modes, private motorized modes, } \\
\text { environmental pollution, safety, and etc.) }\end{array}$ \\
\hline & $\begin{array}{l}\text { Buzasi \& Csete } \\
(2015)\end{array}$ & $\begin{array}{l}\text { Transport indicators for assessing urban transport } \\
\text { sustainability (e.g., Annually freight transport performance, } \\
\text { Environmental tax, pavement condition, and etc.) }\end{array}$ \\
\hline & $\begin{array}{l}\text { Haghshenas \& } \\
\text { Vaziri (2012) }\end{array}$ & $\begin{array}{l}\text { Development of sustainable transportation indicators by } \\
\text { reviewing past research (e.g., emissions of local air } \\
\text { pollutants, transport energy use, time spent in traffic, and } \\
\text { etc.) }\end{array}$ \\
\hline & Jeon (2007) & $\begin{array}{l}\text { Indicators for transportation planning and decision making } \\
\text { considering the sustainability of transportation networks } \\
\text { (e.g., population density, public transit and automobile use, } \\
\text { commute time, and etc.) }\end{array}$ \\
\hline \multirow{2}{*}{ Performance of ITS } & Li et al. (2015) & $\begin{array}{l}\text { Performance indicators for the effective evaluation of ITS } \\
\text { in a smart community (e.g., average travel time, speed } \\
\text { reduction on peak periods, buffering time, and etc.) }\end{array}$ \\
\hline & $\begin{array}{l}\text { Kaparias et al. } \\
\text { (2011) }\end{array}$ & $\begin{array}{l}\text { Key performance indicators for the performance of traffic } \\
\text { management and ITS (e.g., traffic efficiency, traffic safety, } \\
\text { pollution reduction, and etc.) }\end{array}$ \\
\hline
\end{tabular}




\subsection{Smart City Concepts}

In consideration of smart cities as a future dream, there are various smart city concepts among numerous studies related to smart cities. According to Giffinger et al. (2007), the smart city is described as a modern city to enhance the service quality for citizens in terms of various characteristics such as economy, people, governance, mobility, environment, and living. Chen (2010) insisted that the smart city is to improve the quality of life for everyone by optimizing infrastructure operation. Hall (2000) defined the smart city as a city to provide citizens the maximized services by integrating the critical infrastructures (including roads, tunnels, water, and power), optimizing the resources, planning maintenance activities and monitoring security aspects for the city. Also, Harrison et al. (2010) mentioned that the smart city is a city in connection with various types of infrastructures such as physical, social, information technology (IT), and business infrastructures. These smart city concepts are in place of improving public services for citizens in support of various infrastructure systems. Some researchers emphasize that the presence of advanced technologies is essential to define the concept of a smart city. For example, Bakici et al. (2012) described the smart city as a high-tech intensive and advanced city where new technologies connect people, information, and city elements (e.g., economy, community welfare, environment, and infrastructure).

Infrastructure systems supported by advanced technologies are essential for a smart city. The use of IT is beneficial to monitor and optimize the performance of existing infrastructures for better urban functions, which finally drives long-term economic growth, social welfare, and public safety (MarsalLlacuna et al., 2014; Su et al., 2011; Dirks and Keeling, 2009; Kasznar et al., 2021). Partridge (2004) and Washburn et al. (2010) stressed the roles of ICT and computing technologies to enhance the accessibility of the public to infrastructure systems by providing prompt information for infrastructure use. Critical infrastructure systems relying on the industrial IoT assure reliable functioning of the systems that avoid any economic and social disruptions (Falco et al., 2018). Specifically, Agarwal et al. (2015) highlighted the significance of advanced transportation systems to relieve various concerns challenging modern cities. That is, intelligent transportation systems (ITS) are essential for a smart city to enhance a problem-solving 
capability for traffic congestion, fuel consumption, and road accidents in urban areas (Gohar et al., 2018). A network sensing technology application for intelligent traffic control mechanisms in highway systems is a typical example for ITS (Haferkamp et al., 2017).

\subsection{Smart City Indexes}

Smart city indexes had been invented as tools useful for evaluating the smartness of conventional cities. Different organizations and researchers had developed various smart city indexes. Table 2.2 presents some of the well-known indexes that can be found from a discovery search. These indexes are alike in terms of assessing the current development status of smart cities based on numerous indicators and measures for smart city components. The fundamental data used to develop these smart city indexes were collected through interviews with experts and stakeholders, a discovery search focusing on public and project documents, and surveys.

Most smart city indexes are in the form of a hierarchical structure that consists of three different levels. The first level represents a smart city in the components (also referred to as dimensions, characteristics, and themes), such as mobility, environment, people, and living. The second level is to describe the indicators (also referred to as factors, sub-dimensions, and sub-themes) to assess the city according to the components in the first level ( $\mathrm{Li}$ et al., 2020). The third level at the bottom in the hierarchy shows the measures (also referred to as units and descriptions) for the indicators (Giffinger et al., 2007). Figure 2.1 illustrates the hierarchical structure of the smart city indexes. 
Table 2.2. Existing Smart City Indexes

\begin{tabular}{l} 
Smart City Index \\
\hline Global Smart City Index, by \\
Institute for Management \\
Development; Singapore \\
University of Technology and \\
Design \\
Cities in Motion Index, by IESE
\end{tabular}

Purpose

Ranks cities by assessing the perception of city residents of how smart their cities are on two pillars, structure pillar for existing urban infrastructure systems and technical pillar for technological provisions and services to the residents (Bris et al., 2019)

Evaluates the development status of cities moving toward smarter and more sustainable future cities, considering different key city components such as socioeconomic aspects, governance, technologies, and transportation (Berrone et al., 2019)

Smart City Strategy Index, by Roland Berger

Measures a strategic approach of urban centers to solve various urban challenges through innovations (e.g., digital services, smart traffic management system, and green infrastructure) (Roland Berger, 2019)

Global Smart Sustainable City Index, by International Telecommunication Union Smart City Index, by CITYkeys Assesses the efficiency and sustainability of current city operations, which is then utilized for cities to develop further their performance (Smiciklas and Imran, 2018)

Measures the progress of city development to smartness through effective policies and best practices (Bosch et al., 2017)

Smart Cities Index, by Indian School of Business Monitors the investment effects of Indian cities on advancing smart cities over time (Mohan et al., 2017)

Evaluates the strategies of UK cities for smart city programs and assesses their actual achievements (Woods et al., 2017)

Assesses city efforts in improving various smart city components, such as environment, mobility, government, economy, people, and living (Smart Cities Council, 2014)

Provides a self-assessment model to evaluate the maturity levels (e.g., ad-hoc, opportunistic, purposeful and repeatable, operationalized, and optimized) of Scottish cities (Urban Tide, 2014)

European Smart City Index, by Evaluates the strengths and weaknesses of European medium-sized Giffinger et al. cities as smart cities (Giffinger et al., 2007)

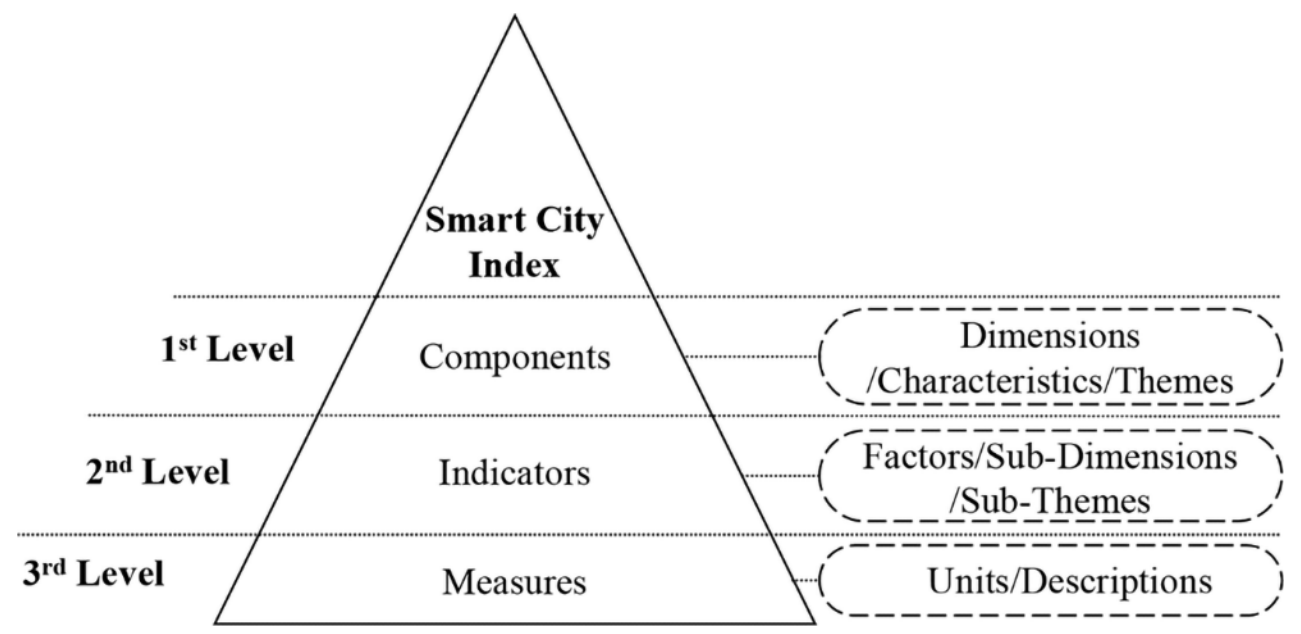

Figure 2.1. A Hierarchical Structure of Smart City Indexes 
The smart city components of these indexes are variant, depending on the specific purposes to evaluate smart cities, as discussed in Table 2.3. For example, the European Smart City Index, Smart City Index Master Indicators, and Indian Smart Cities Index use six smart city components that include environment, mobility, governance, economy, living, and people (Giffinger et al., 2007; Smart Cities Council, 2014; and Mohan et al., 2017). The IESE Cities in Motion Index has additional components such as technology, international outreach, and urban planning to these six components (Berrone et al., 2019). On the other hand, the CITYKeys Smart City Index consists of the components such as people, planet, prosperity, governance, and propagation (Bosch et al., 2017). The indicators at the second level for each component are diverse in keeping with the different perspectives to represent the component. Sharifi (2020) investigated 34 smart city assessment tools, including smart city indexes, and identified a total of 98 various indicators. Table 2.3 shows some indicator samples for the smart city components, environment, mobility, living, and governance. I found that these indicators are exhaustive to describe each component so that the current development status of a whole city advancing to smartness can be evaluated well. However, the scopes of these indicators are too coarse to apply for a specific target such as urban roads, health systems, or broadband services that need fine-tune strategies based on tailored diagnostics on current development status. 
Table 2.3. Indicator Sample of the Selected Smart City Components

\begin{tabular}{ll}
\hline Component & Indicator \\
\hline Environment & Sustainable natural resource management \\
& $\begin{array}{l}\text { Penetration level of clean and renewable energy sources } \\
\text { ICT-enabled environmental monitoring infrastructure and activities } \\
\\
\text { GHG emissions ((CO2, N2O, CH4) footprint, concentration, etc.) }\end{array}$ \\
\hline Mobility & Public transport system and its quality, diversity, and multi-modality \\
& Smartphone penetration \\
& Performance, safety, and efficiency of public transportation \\
& Real-time information about transit services and parking \\
& Road traffic efficiency, travel time, congestion levels, congestion management \\
\hline Governance & Public participation and stakeholder engagement in decision making \\
& E-governance and online civic engagement and feedback system \\
& Governmental transparency \\
\hline Economy & ICT-enabled innovation leading to new businesses and market opportunities \\
& Share of e-business and E-commerce transactions \\
& Funding for smart city projects (public/private finance, crowdsourced, etc.) \\
\hline Living & Affordable and sustainable access to services and utilities \\
& Housing quality (area per capita), informal housing, and slum reduction \\
& Healthcare services and infrastructure per capita \\
& Satisfaction (perception of) with quality of life and urban services \\
\hline
\end{tabular}

\subsection{Prioritization Models}

The efficient development of smart cities starts from understanding the needs or challenges that cities have currently or in the future and prioritizing them to address through strategic planning of investments. The needs or challenges can be defined as various terminologies such as components, strategies, and risks, depending on prioritizing objectives and focuses. Components are service areas that a city needs to advance to evolve to a smart city, such as environment, economy, government, mobility, people, and living. Multiple smart city components are generally used to evaluate the smartness of a city (Albino et al., 2015). Deveci et al. (2020) stated that selecting what components should be considered depends on evaluation objectives, but all selected components still need to be prioritized for efficient investment decision-making. They utilized the Interval Agreement Approach (IAA) to prioritize different smart city components based on the data collected from repeated surveys in multi-criteria decision-making 
(MCDM). Kim et al. (2019) also asserted the importance of prioritizing various components essential for smart cities, given a need for massive financial inputs. They analyzed the priorities of the five components and 22 sub-components using the expert survey and Analytic Hierarchy Process (AHP) techniques.

On the other hand, Mukul et al. (2021) identified and prioritized the strategies using the Fuzzy MCDM techniques such as fuzzy Simple Additive Weighting (SAW) and fuzzy Evaluation based on Distance from Average Solution (EDAS). They defined strategies as the efforts required for cities to achieve the goals of smart cities, such as high-quality life, natural resource management, and establishment of smart communication infrastructures, in a more effective, safe, and ecologically responsible manner. The strategies prioritized in connection with the smart city goals include: building an efficient smart city ecosystem, increasing smart city transformation capacity, creating a suitable and supportive environment in smart city transformation, and ensuring smart city transformation in urban services. Gupta et al. (2020) mentioned that successful implementation of smart city projects needs the understanding of current risks that can be occurred during the projects. They identified the risks that can prevent the successful implementation of smart city projects in eight groups (e.g., financial, partnership and resources, social, technology, scheduling and execution, institutional, environmental, and political) through the Smart City Mission launched in India. The risk groups were prioritized using the Risk Priority Matrix tool that assessed the occurrence likelihoods of the identified risks on smart city projects. They also analyzed the priorities of the risk groups, considering project scales, small and large, by using the co-occurrence network approach; for example, analysis of which risk group out of the eight risk groups were more frequently connected with large-scale cities (or small-scale cities).

Specific to transportation infrastructures that are essential for smart city development (Gohar et al., 2018), there are also studies presenting prioritization models for different subject targets using various techniques. For example, Khademi et al. (2010) analyzed the priorities of user services of the Intelligent Transportation System (ITS) by using the Analytic Network Process (ANP) approach. The user services prioritized include traveler information, traffic management, and emergency vehicle management. Krmac 
and Djordjević (2017) developed indicators to assess railways for ITS. They applied the priorities of the indicators that were determined by the AHP approach for the assessment. Curiel-Esparza et al. (2015) analyzed the priorities of urban transport systems, such as pedestrian roads, bicycle networks, bus transport, underground transport (e.g., metro), and parking, to enhance sustainable mobility (e.g., economy, travel quality, and sustainability) in urban areas. They employed the pairwise comparison method (e.g., AHP) with the Delphi technique to identify the relative importance of the transport systems considering multicriteria such as economy, engineering, environment, social, and risk.

In summary, the literature review on prioritization models for smart city development and ITS found that most of the studies were relied on approaches using subjective inputs. The use of subjective inputs in prioritizing can be viable if well-defined priority evaluation criteria do not exist. However, prioritization approaches established based on empirical data can generally provide more exquisite priorities, not distorting priority results due to subjectivity (Jahedi and Méndez, 2014). Also, the prioritization approaches based on subjective inputs normally undergo additional analyses (e.g., sensitivity analysis) to enhance the quality of priority results, which makes prioritization processes more complicated (Siksnelyte-Butkiene et al., 2020). 


\section{CHAPTER 3: HIERARCHY TABLE DEVELOPMENT}

This chapter presents the procedures suggested to develop the hierarchy table in detail and the application of the procedures showing the activities conducted. As the hierarch table is applied to assess the current development status of urban roads, the hierarch table is a bedrock of the advanced system prioritization framework in Chapter 4. The chapter also includes the discussions made for the questions raised in developing the hierarchy table.

\subsection{Procedures to Develop a Hierarchy Table for Urban Roads.}

The keyword network analysis, which is one of the text mining techniques to derive information and knowledge from unstructured texts in documents and databases (Magerman et al., 2011), is a primary approach used to develop a hierarchy table in this paper. The hierarchy table consists of smart city components, indicators, and measures at three different levels. Therefore, as illustrated in Figure 3.1, a hierarchy table development requires three phases: data preparation, data analysis, and hierarchy table. Each phase includes multiple tasks to provide phase outputs to the subsequent phases. Figure 3.1 also includes one feedback loop between the main sentence classification in Phase 1 and the keyword frequency evaluation in Phase 2, which is elaborated in the subsection, Data Analysis Phase. 


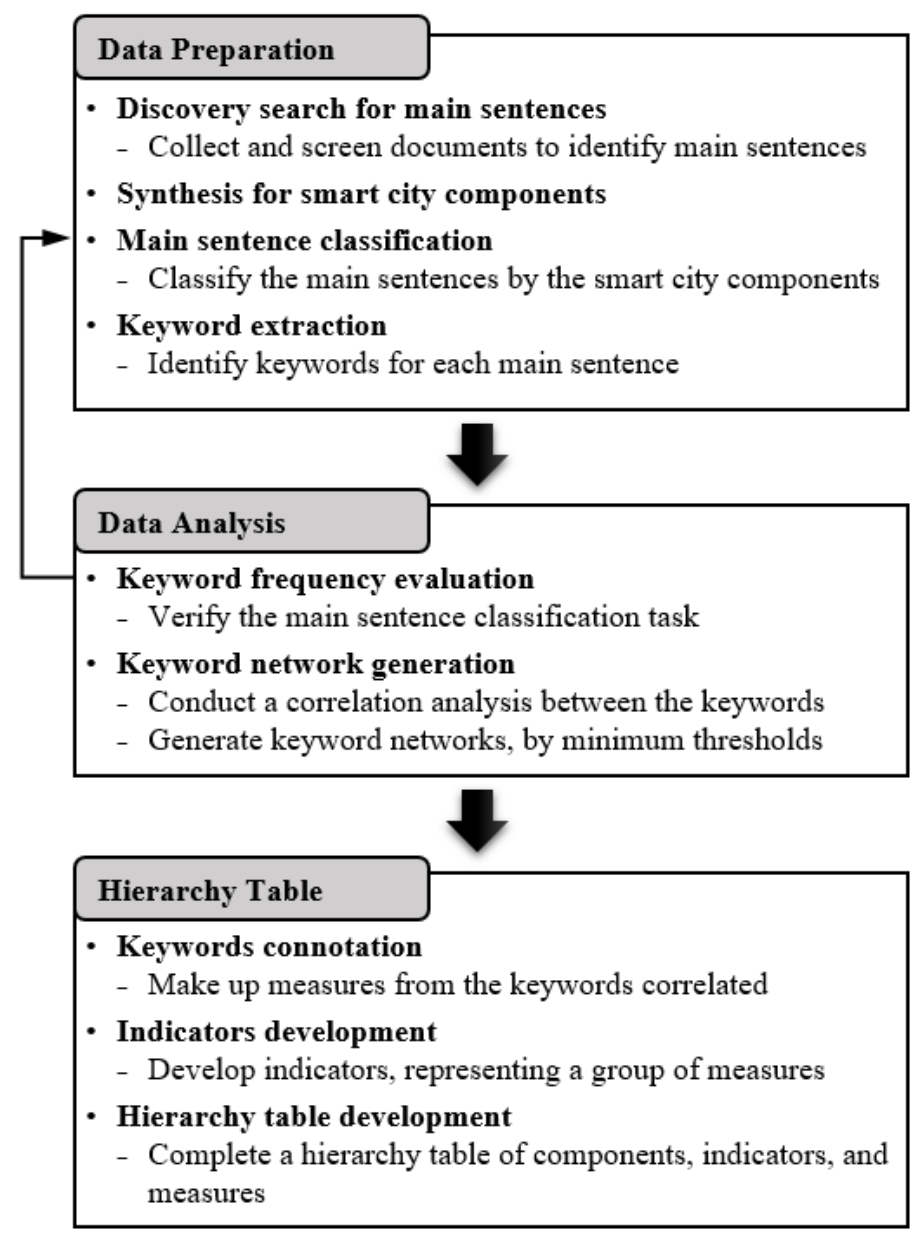

Figure 3.1. Phases for a Hierarchy Table Development

\subsubsection{Data Preparation Phase}

The data preparation phase is designed to derive smart city components and provide keywords in a format to the data analysis phase. The derivation of smart city components is a prerequisite in developing a hierarchy table as the indicators and measures are used to evaluate the current development status of urban roads and identify advanced systems for urban road innovation that consequently benefit a smart city. The general approaches to derive smart city components can be the development of new components or synthesis from existing smart city indexes, using the data obtained from literature review, interviews with experts or expert groups, and surveys. As smart city components are variant depending on the different purposes to use them, the properties of components are limited to the evaluation target, urban roads. 
The discovery search task is to collect and screen the documents that include the main sentences describing the benefits of urban roads for smart cities. That is, the collected documents should be focused on urban roads for smart cities, and documents that are not relevant to the scope are eliminated to improve the quality of data. For the collection of documents, various search engines and public databases, such as the transportation facilities or smart cities, related to the research scope can be utilized. The main sentences are then identified from the collected and screened documents, and the primary benefits of the main sentences are captured to classify them by smart city components. Lastly, the main sentences are processed to separate keywords, which is called keyword extraction. The keyword extraction task first fragments the main sentence into words and/or phrases, containing meaningful information such as benefits, subjects, and objects. The word/phrases from each main sentence are reviewed for any further processing (e.g., fragmenting phrases and combining word + word or word + phrase) to better deliver the original intention of the sentence. Then, the keywords from different sentences at each smart city component are evaluated for synonyms so that the different keywords of the same meaning can be unified into identical keywords, which is essential for proper data analysis.

\subsubsection{Data Analysis Phase}

The data analysis phase consists of the keyword frequency evaluation and keyword network generation tasks. The keyword frequency evaluation task is to check whether the main sentence classification in Phase 1 is well performed, which is important to develop indicators and measures fitting into the associated smart city component. The task first removes less frequent keywords for two reasons, enhancing data analysis reliability by excluding these keywords included in documents by chance and generating visually discernable networks (i.e., nodes for keywords and lines connecting nodes) to efficiently identify information (Kim et al., 2005; Benchimol et al., 2020). Then, the frequency of survived keywords at each smart city component is estimated for top-ten frequent keywords to compare with the central words/phrases that define the smart city component. The assumption to verify the goodness of the main 
sentence classification performance is that high-frequent keywords for one component are well-matched with the central words/phrases of the component and not seen in any other components. The failure in this evaluation requires going back to the main sentence classification task for reclassification.

The keyword network generation requires a correlation analysis to investigate any connections between the keywords extracted so that the correlated keywords are used to make up indicators and measures in Phase 3. There are various methods applicable to keyword correlation analysis, including Jaccard similarity, cosine similarity, and Pearson correlation coefficient. The higher correlation values indicate the stronger connection between the two keywords being used together to provide information. However, when interpreting correlation values, there should be the following two considerations. First, correlation values are unreliable for smaller sample sizes due to the higher chances of sampling errors (Knudson and Lindsey, 2014). Second, correlation values are higher for smaller sample sizes that are likely to have less variability of samples (Bujang and Baharum, 2016; Winter et al., 2016). The discovery search in Phase 1 assumes that samples (i.e., numbers of main sentences) are different across the smart city components, depending on the influential extent of intelligent urban roads to a smart city. Therefore, employing minimum thresholds of correlation values to limit the keywords in network generation is necessary to maximize the reliability of the keyword connotation in Phase 3.

\subsubsection{Hierarchy Table}

The hierarchy table phase takes three tasks: 1) keywords connotation, 2) indicators development, and 3) hierarchy table development. The keywords connotation task is to create measures through a semantic approach that captures information by combining and refining the words correlated. Thus, the keyword networks generated in Phase 2 are the sources to make up measures, which are called immature measures in this paper, for each smart city component. Then, the immature measures are post-processed to evaluate their commonality and conveyance based on the knowledge obtained from a measure-oriented 
discovery search, which results in complete measures. The complete measures in each smart city component need to group to develop indicators. The approaches to group measures can be based on the clusters of measures in a keyword network or the measures with similar benefits or requiring the same data types. The formalization of indicators should clearly represent a group of measures, encompassing all their properties. Phrasing indicators also refers to the indicators in the existing smart city indexes and other available sources (e.g., public transportation documents and websites) for possible alignment with the indexes. Finally, the indicators and measures are organized into a hierarchy table, associating them to matching smart city components.

\subsection{Development of Indicators and Measures for Hierarchy Table}

\subsubsection{Phase 1: Data preparation}

\section{Discovery Search for Main Sentences}

The discovery search process had a comprehensive literature review on various studies such as public reports, handbooks, journal articles, and conference papers. The primary databases used for the document collection were the Google Scholar and U.S. Department of Transportation (USDOT) ITS Development Evaluation Database. In particular, the ITS Development Evaluation Database of USDOT, which is accessible at https://www.itskrs.its.dot.gov/benefits, was selected as a primary source because the ITS is closely related to smart city development, as many researchers mentioned (Agarwal et al., 2015; Gohar et al., 2018). The USDOT database contains various ITS-related studies explaining benefits for ITS deployment and operation in diverse cities. The discovery search was limited to the studies that have been published since 2007 when the terminology, smart city index (e.g., the European Smart City Index), started to appear more often, according to the literature review. As a result, a total of 527 documents were collected, which was finally processed to 510 main sentences by removing the documents not related to urban roads. 


\section{Synthesis for Smart City Components}

As another pillar to prepare for the development of a hierarchy table in this phase, the synthesis study to derive smart city components was conducted using the documents of the smart city indexes in Table 1. A total of 37 components was identified from these documents, and some of the components of similar properties were combined. For example, the components such as environment, planet, sustainability, and energy were aligned altogether. The Smart Sustainable City Index described the environment component as urban services related to renewable and sustainable sources, energy consumptions, and greenhouse gas emissions to improve the overall environmental quality of cities (Smiciklas and Imran, 2018). The planet component in the CITYKeys Smart City Index represents energy consumptions, CO2 emissions, and renewable energy (Bosch et al., 2017). The UK Smart Cities Index (Woods et al., 2017) includes sustainability and energy as the separate components, defining sustainability as the environmental programs and circular economy and energy as new approaches to city energies. However, the indicators for sustainability are alike as the indicators in environment, and some other smart city indexes, such as the European Smart City Index, Indian Smart Cities Index, and CITYKeys Smart City Index, discussed sustainability in the environment component. Figure 3.2 shows all the components along with the numbers of the documents appearing for each component. The components or component groups that appeared in more than five smart city indexes are environment/planet/energy/sustainability, mobility/transportation, governance, economy, living/culture/society/housing, people/citizen/human, and health/safety. On the other hand, there exist the components considered by only one smart city index. However, it does not imply that these components can be regarded as less important to describe a smart city because the selection of appropriate components relies on the design goals of smart city indexes. 


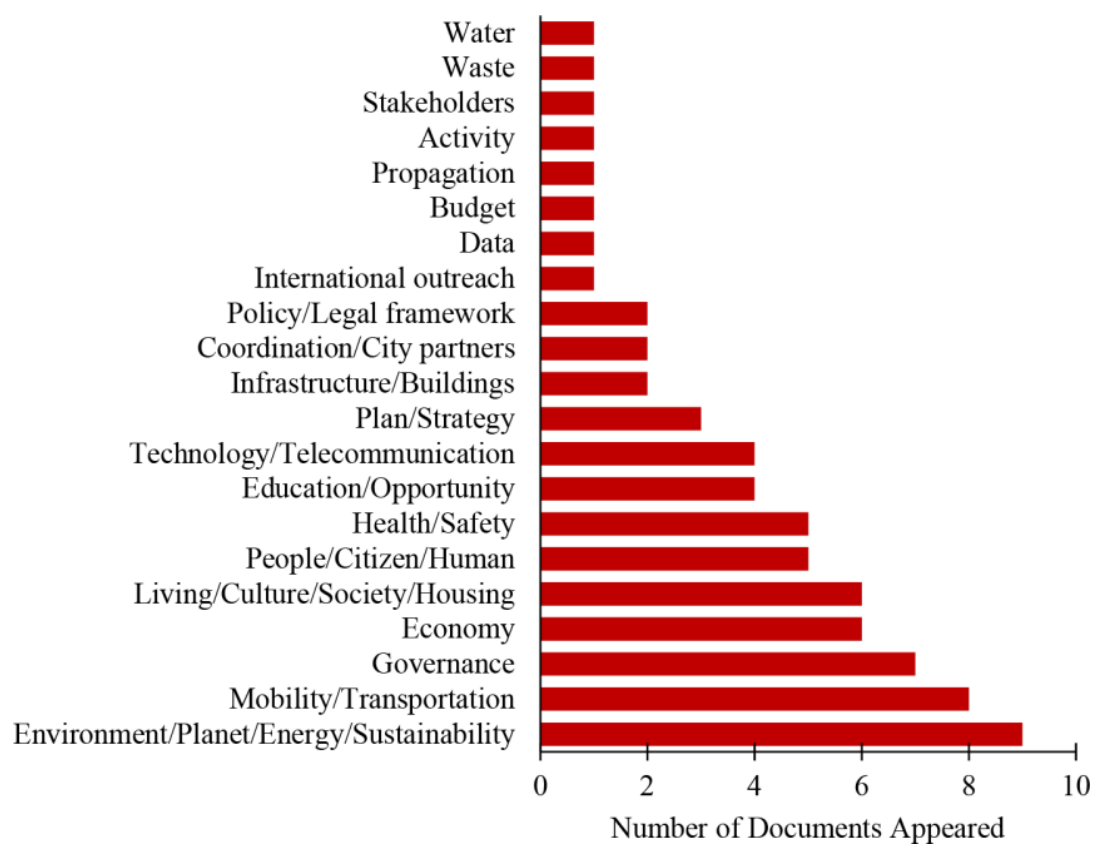

Figure 3.2. Smart City Components retrieved from the Smart City Indexes in

The selection of smart city components in this paper was made, considering the purpose of developing a hierarchy table of indicators and measures that is to contribute to establishing a smart city by innovating urban roads through the application of advanced systems. Therefore, I first retrieved the national Federal-aid Highway Program performance goals, including safety, infrastructure condition, congestion reduction, system reliability, freight movement and economic vitality, environmental sustainability, and reduced project delivery delays (23USC $§ 150(b))$. Then, the national goals were reviewed by relating them to the indicators and measures of the components presented in the existing smart city indexes. The components with any relating indicators or measures were survived. For example, the system reliability of the national goals is described as the efficiency of a surface transportation system that was connected to the efficiency indicator (e.g., trip length and travel time) in the mobility component. On the other hand, there was no connection between the indicators or measures in the people component and the national goals, so that the component was removed. As a result, the synthesis process finalized the selection of the smart city components to the environment, mobility, governance, economy, and living. It should be noted that the 
component terms of similar properties were combined into more general terms. The description of each component is as follows:

- The environment component focuses on solving the pollution problems in urban areas, reducing energy consumptions using renewable and sustainable energy resources (e.g., solar power, wind power, etc.), enhancing resource management for the efficient use of public utilities (e.g., water and electricity), and protecting the environment (Zubizarreta et al., 2016).

- The mobility component aims to improve the overall urban network for traffic congestions, traffic flows, and vehicle speeds (Faria et al., 2017). The component also considers the convenient movement and accessibility to transit for citizens as well as transport efficiency (Albino et al., 2015; Benevolo et al., 2016; Lopez-Carreiro and Monzon, 2018).

- The governance component is related to improving the efficiency of governments in planning, strategies, management (i.e., asset and disaster management), and decision-making to address the needs of citizens (e.g., security, safety, convenience, and policies) (Berrone et al., 2019; Pereira et al., 2018). This component also includes online platforms to communicate with citizens (e.g., immediate responses to citizens' demands and prompt information delivery to citizens).

- The economy component supports urban economic development by providing a sustainable network of urban roads and public transport to commuters and businesses, enhancing labor productivity, and strengthening the accessibility to national and international trade markets. (Zubizarreta et al., 2016; 23USC $§ 150(b))$. This component also includes the innovation of road facilities (e.g., parking meters and toll stations) to increase city revenues.

- The living component has a strong relationship with the quality of life for citizens, so it utilizes advanced systems and management strategies to achieve the convenience and safety of citizens. Public healthcare, cultural life, security, and housing also can be included in this component. Other elements to improve the social welfare of citizens, such as emergency response, public healthcare, education, security, cultural life, and housing, can be included in this component (Bruni et al., 2017). 


\section{Main Sentences Classification}

The selected smart city components were then used to categorize the main sentences extracted. The categorization looked into the primary intention of the main sentence. For example, the sentence "Smart streetlights are to optimize the problem of power consumption" was classified as the environment component, while the sentence "Evacuation strategies and supporting infrastructures can mitigate the effect of disaster" was assorted to the governance component. Figure 3.3 shows the classification result of the main sentences. The mobility component includes the highest number of sentences (273 sentences), representing that the mobility of urban roads has the foremost contribution to a smart city.

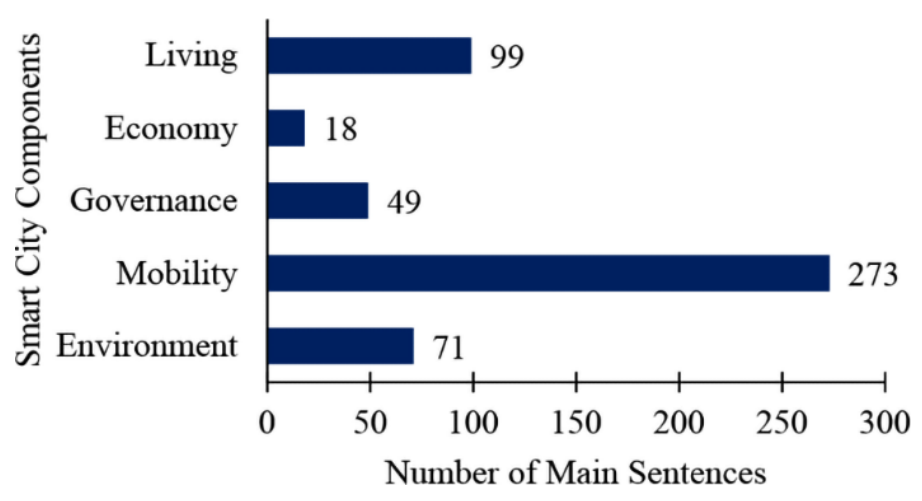

Figure 3.3. Main Sentences Classified by Smart City Components

\section{Keyword Extraction}

The main sentences by the smart city components were extracted into the data format of keywords through the keyword extraction process that generally requires delicate work for a proper data analysis, especially term frequency and correlation analysis. Therefore, the prepositions (e.g., in, on, at, and to), articles (e.g., the and $a$ ), adverbs (e.g., very and well), and conjunctions (e.g., and, but, or, and while) were first removed to break the main sentences into words and/or phrases. Then, verb and adjective words were 
connected to contextually relevant nouns as needed; otherwise, they were removed. Also, synonymous words/phrases were combined into a word/phrase that conveys meaning better or is used more commonly. Figure 3.4 shows an example of the keyword extraction process. The exemplary sentence was fragmented into words and phrases that included verbs and nouns. The verb, collect, was transformed into a noun to connect it to traffic data while improve was removed. Then, the phrases, traffic flow and queue length, were combined into the traffic flow.

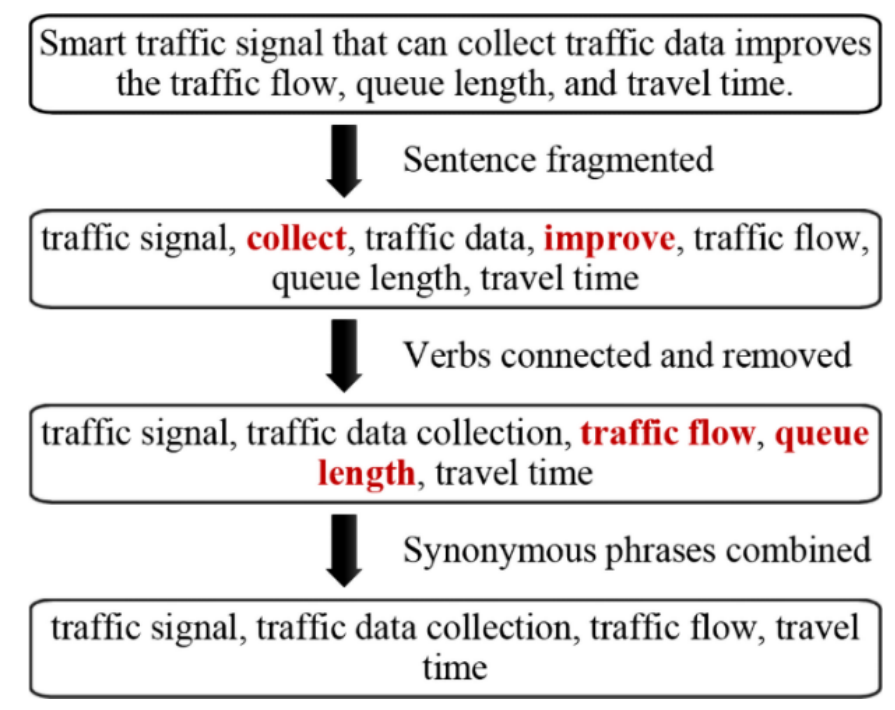

Figure 3.4. Example for the Keyword Extraction Process

\subsubsection{Phase 2: Data Analysis}

The data analysis phase took the tasks such as keyword frequency evaluation and keyword network generation. The tasks related to the data analysis utilized RStuio, and the keyword networks were generated using Gephi. Both RStudio and Gephi are open-source applications available for public use.

\section{Keyword Frequency Evaluation}

The keyword frequency evaluation was first needed to process the keywords extracted in Phase 1 to a document-term matrix, a mathematical matrix representing the frequency of terms in a collection of 
documents (Benchimol et al., 2020). The terms and documents are represented as keywords and sentences for this paper. Figure 3.5 shows how keywords extracted from main sentences are formulated in a document-term matrix. Seven keywords were retrieved from the three main sentences, creating term columns for the three documents in rows. The number " 1 " assigned to the cells represents that a document includes the term; otherwise, "0". A term of mostly zero values in a matrix is called a sparse term (i.e., less frequent term). Removing sparse terms utilizes a threshold called sparsity. This paper used the sparsity of 0.99, above which keywords were eliminated (i.e., keywords more sparse than 0.99). For example, the sparsity of 0.99 for the mobility component with 273 main sentences (see Figure 3.3), which was calculated as $273 \times(1-0.99)=2.73$, removed the keywords appearing in only one or two main sentences. Similarly, the sparsity value was applied for all other smart city components.

\begin{tabular}{|l|c|}
\hline \multicolumn{1}{|c|}{ Main Sentences } & \multicolumn{1}{|c|}{ Keywords Extracted } \\
\hline $\begin{array}{l}\text { Document 1 (= Sentence 1) } \\
\text { The environment for a smart city reduces pollution and energy consumption. }\end{array}$ & $\begin{array}{c}\text { environment, smart_city, } \\
\text { pollution, energy_consumption }\end{array}$ \\
\hline \begin{tabular}{|l|l|}
\hline $\begin{array}{l}\text { Document 2 (= Sentence 2) } \\
\text { The environment for a smart city is related to energy and resources. }\end{array}$ \\
\hline $\begin{array}{l}\text { Document 3 (= Sentence 3) } \\
\text { Urban roads reduce energy consumption. }\end{array}$
\end{tabular} & $\begin{array}{c}\text { environment, smart_city, } \\
\text { energy, resources }\end{array}$ \\
\hline
\end{tabular}

Process to document-term matrix

\begin{tabular}{|c|c|c|c|c|c|c|c|}
\hline & environment & $\begin{array}{c}\text { smart_ } \\
\text { city }\end{array}$ & pollution & $\begin{array}{c}\text { energy_ } \\
\text { consumption }\end{array}$ & energy & resources & $\begin{array}{c}\text { urban_- } \\
\text { road }\end{array}$ \\
\hline D1 & 1 & 1 & 1 & 1 & 0 & 0 & 0 \\
\hline D2 & 1 & 1 & 0 & 0 & 1 & 1 & 0 \\
\hline D3 & 0 & 0 & 0 & 1 & 0 & 0 & 1 \\
\hline
\end{tabular}

Figure 3.5. Document-Term Matrix Development

The frequencies of the survived keywords were then estimated to verify the quality of the main sentence classification task. Figure 3.6 shows the ten keywords in high frequencies for the smart city 
components. The central words/phrases to describe the smart city components are present below the circles of the components for comparison with the top ten frequent keywords. It should be noted that the keywords of single words make information in relation to other keywords due to the wide connectivity of these keywords. That is why some keywords of single words, such as road, vehicle, intersection, and maintenance, are included in more than one component. At the same time, the keyword extraction in this paper created the keywords of phrases when they generally have specific information to deliver together. It indicates that the phrase-keywords of a component should be listed as high-frequent keywords matching with the central words/phrases of the component, which was observed in the top-ten keywords in Figure 3.6. For example, the environment component clearly shows the well-matching keywords, such as fuel consumption, road lighting, electricity generation, eco-signal operation, and energy-saving, with the central words/phrases. On the other hand, it seems that the traffic signal keyword is more relevant to the mobility component. However, the keyword also matches with the central word, pollution problems, by reducing vehicle fuel consumption through efficient traffic signal control. 


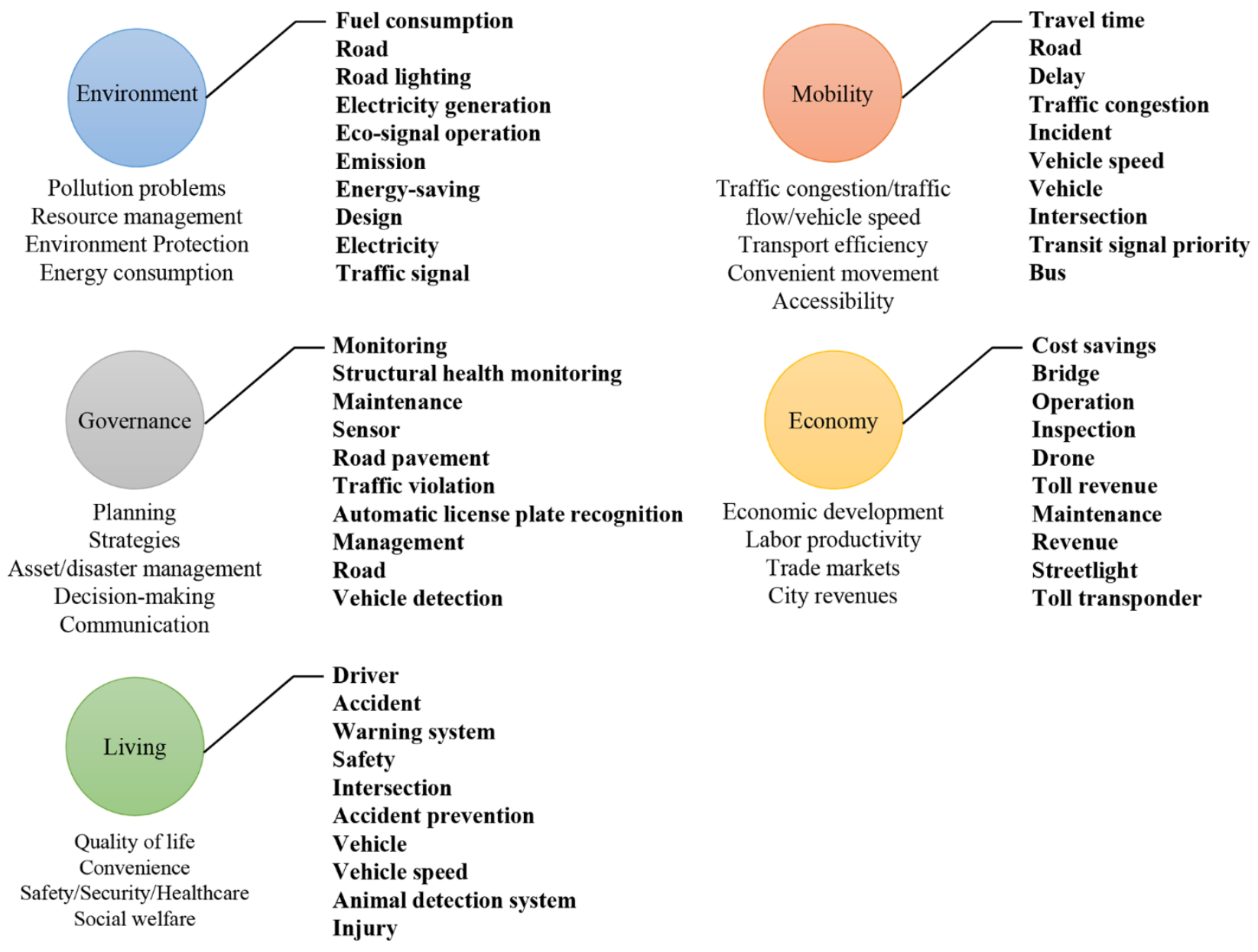

Figure 3.6. Top-ten Keywords for each Smart City Component

\section{Keyword Network Generation}

A cosine similarity metric was the method used for the correlation analysis between keywords. A cosine similarity metric is frequently utilized in data mining and information retrieval by measuring the similarity of two documents (Singhal, 2001). Cosine similarity has a value between 0 and 1, and a value closer to 0 means there is a weaker correlation between two keywords, and a value closer to 1 means that they have a stronger correlation. Upon completion of the correlation analysis, a cosine similarity threshold value for each smart city component was set to generate an informative keyword network. A cosine similarity threshold is a minimum limit to cut off the keywords in lower correlations to avoid displaying 
insignificant information in a network. The cosine similarity thresholds were determined by a receiver operating characteristic (ROC) analysis. ROC analysis is a useful technique to evaluate binary classification with varying discrimination thresholds (Kumar and Indrayan, 2011). Adapting the steps presented in Orkphol and Yang (2019), the procedures considered to find a similarity threshold in this paper were: (1) select a small sample of keywords in pairs at random, (2) bring a cosine similarity value for each paired keyword (3) assign a binary score (1 if relevant, 0 if not relevant) for each paired keyword by knowledgebased validation (i.e., human judgment) without seeing its cosine similarity value, and (4) conduct ROC analysis using the cosine similarity values and binary scores to obtain similarity threshold. During the procedure, the ROC analysis tries to find a cut-off cosine similarity value where the sample paired keywords are divided into the relevant and irrelevant groups by the assigned binary scores. In general, the ROC analysis determines a cut-off value at the degree of separability above 0.7 (Mandrekar, 2010). Further detail can be found in the studies of Streiner and Cairney (2007) and Orkphol and Yang (2019).

Table 3.1 shows the samples of the paired keywords with the cosine similarity values estimated by the correlation analysis and the binary scores assigned by human knowledge. As a result, the minimum similarity threshold values applied for the keyword networks were $0.211,0.113,0.335,0.360$, and 0.193 for the environment, mobility, governance, economy, and living components, respectively. The keyword networks for all five smart city components were generated based on the minimum similarity threshold values, as presented in Figure 3.7 through Figure 3.11. The networks are composed of the nodes for the keywords and the edges for the correlations between the keywords. The thicker the edges, the stronger the relationship between keywords. The various colors represent different clusters of the co-occurring keywords so that they were the basis for developing indicators and measures in Phase 3. 
Table 3.1. Binary Scores for Sample Paired Keywords

Sample of Paired Keyword Cosine Similarity Value Binary Score

\begin{tabular}{cccc}
\hline Keyword 1 & Keyword 2 & & \\
\hline driver & traffic_flow & 0.141 & 1 \\
alert & traffic_signal & 0.076 & 0 \\
corridor & clearance_time & 0.089 & 0 \\
traffic_flow & intersection & 0.041 & 0 \\
workzone & alternate_route & 0.182 & 1 \\
lane & toll & 0.154 & 0 \\
vehicle_speed & workzone & 0.199 & 1 \\
drvier & alternate_route & 0.350 & 1 \\
\hline
\end{tabular}

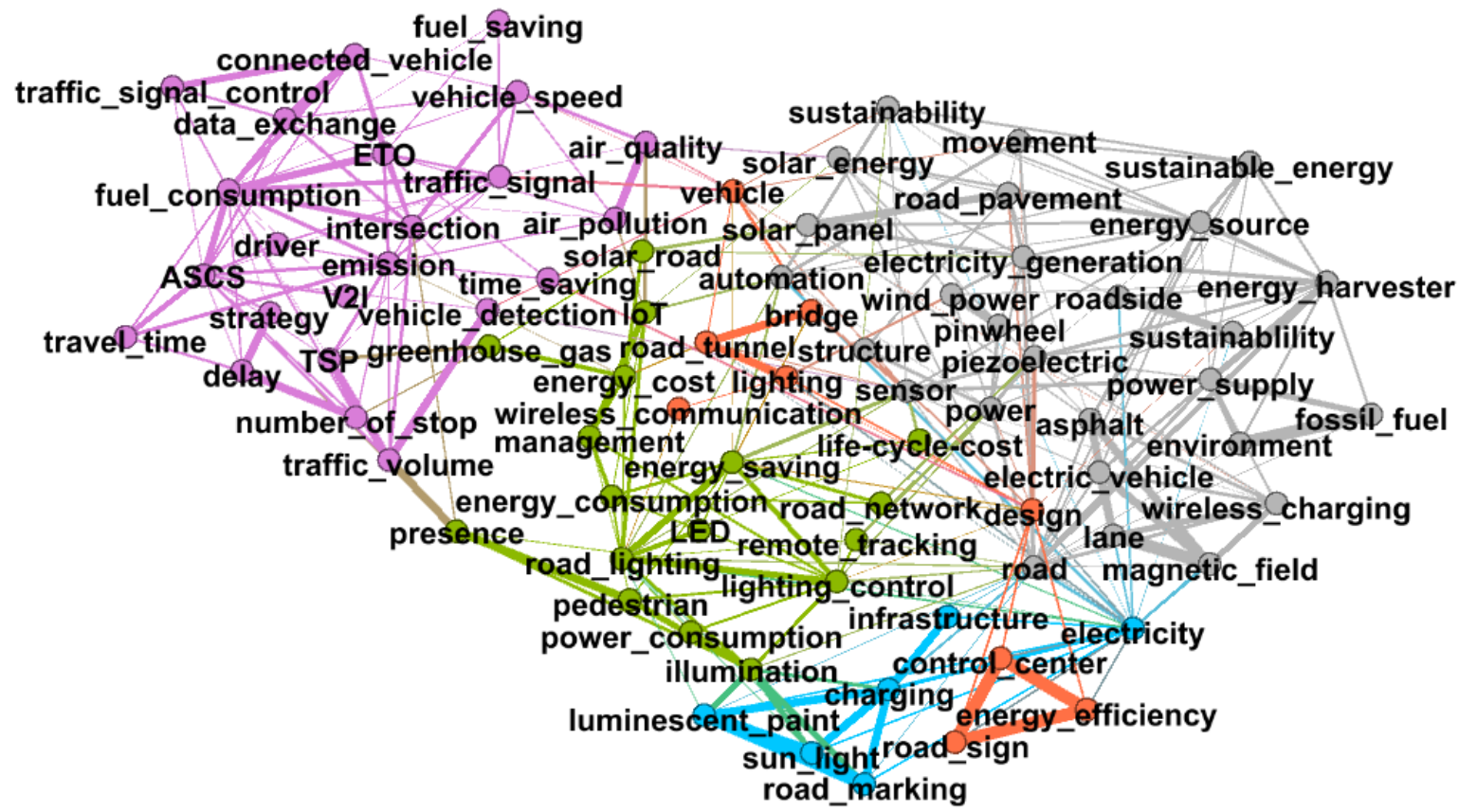

Figure 3.7. Network for the Environment Component 


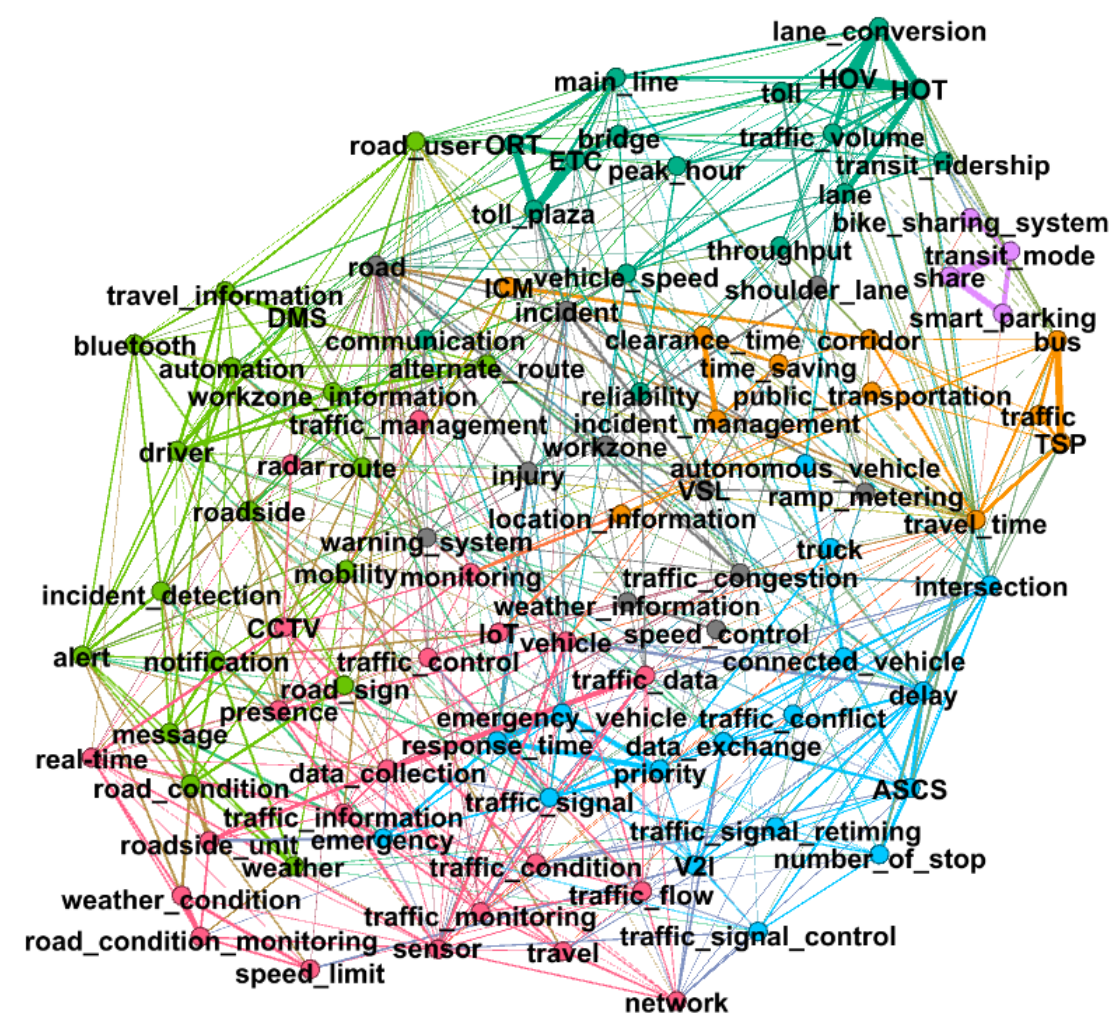

Figure 3.8. Network for the Mobility Component

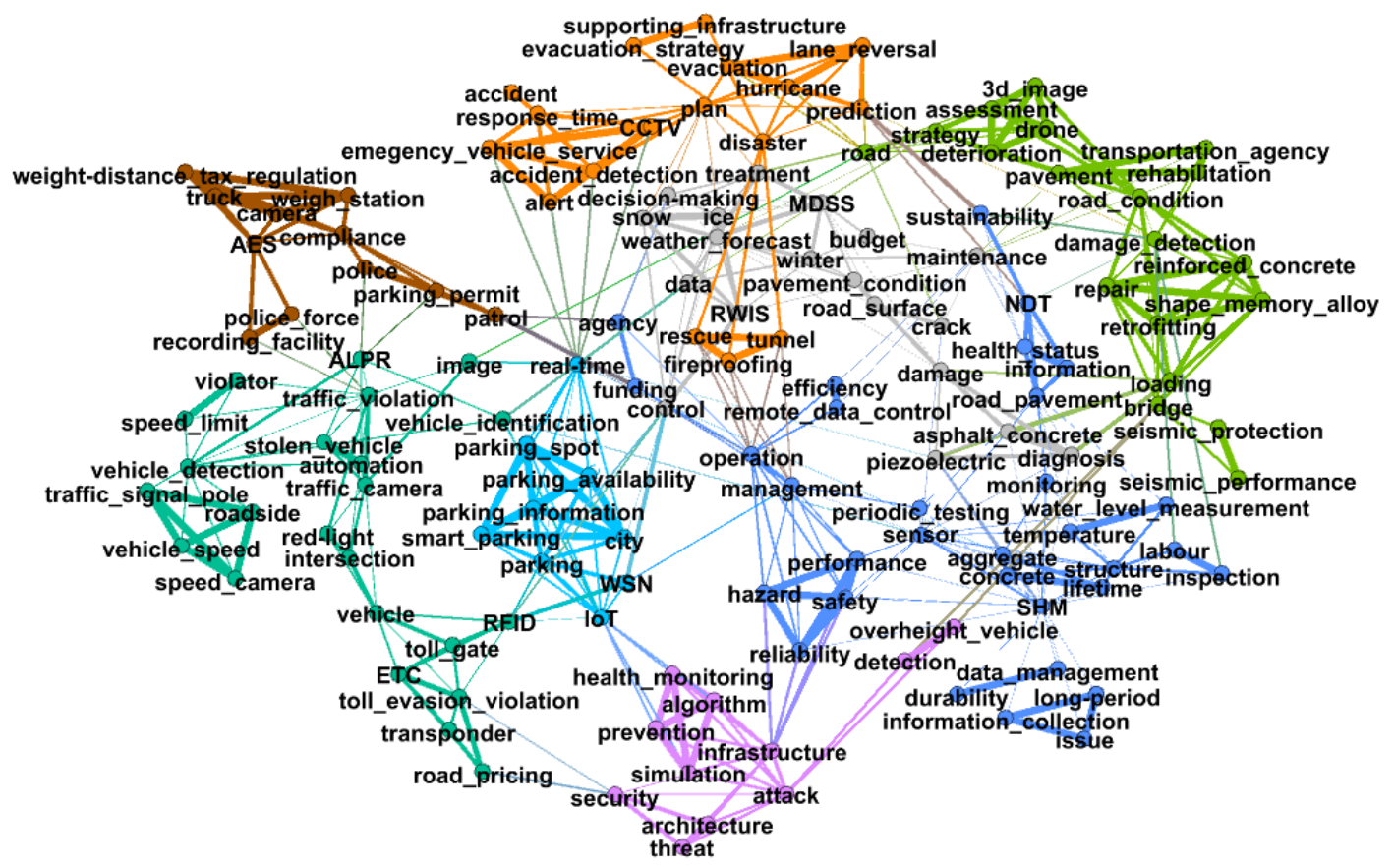

Figure 3.9. Network for the Governance Component 


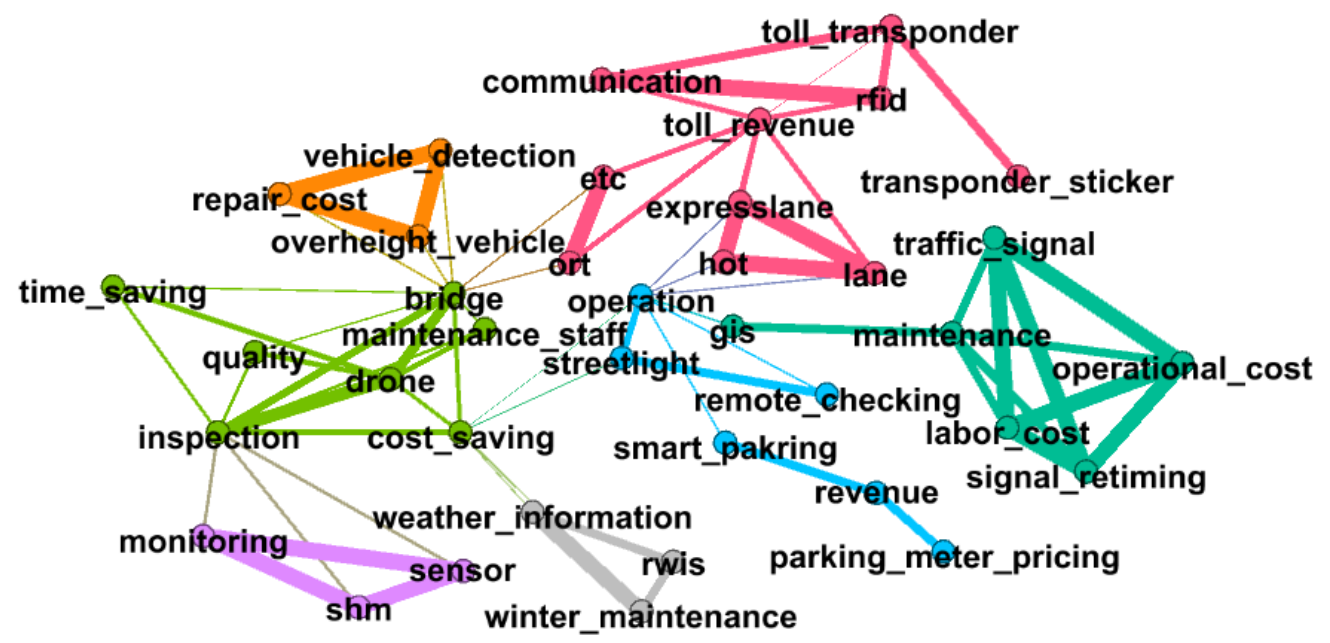

Figure 3.10. Network for the Economy Component

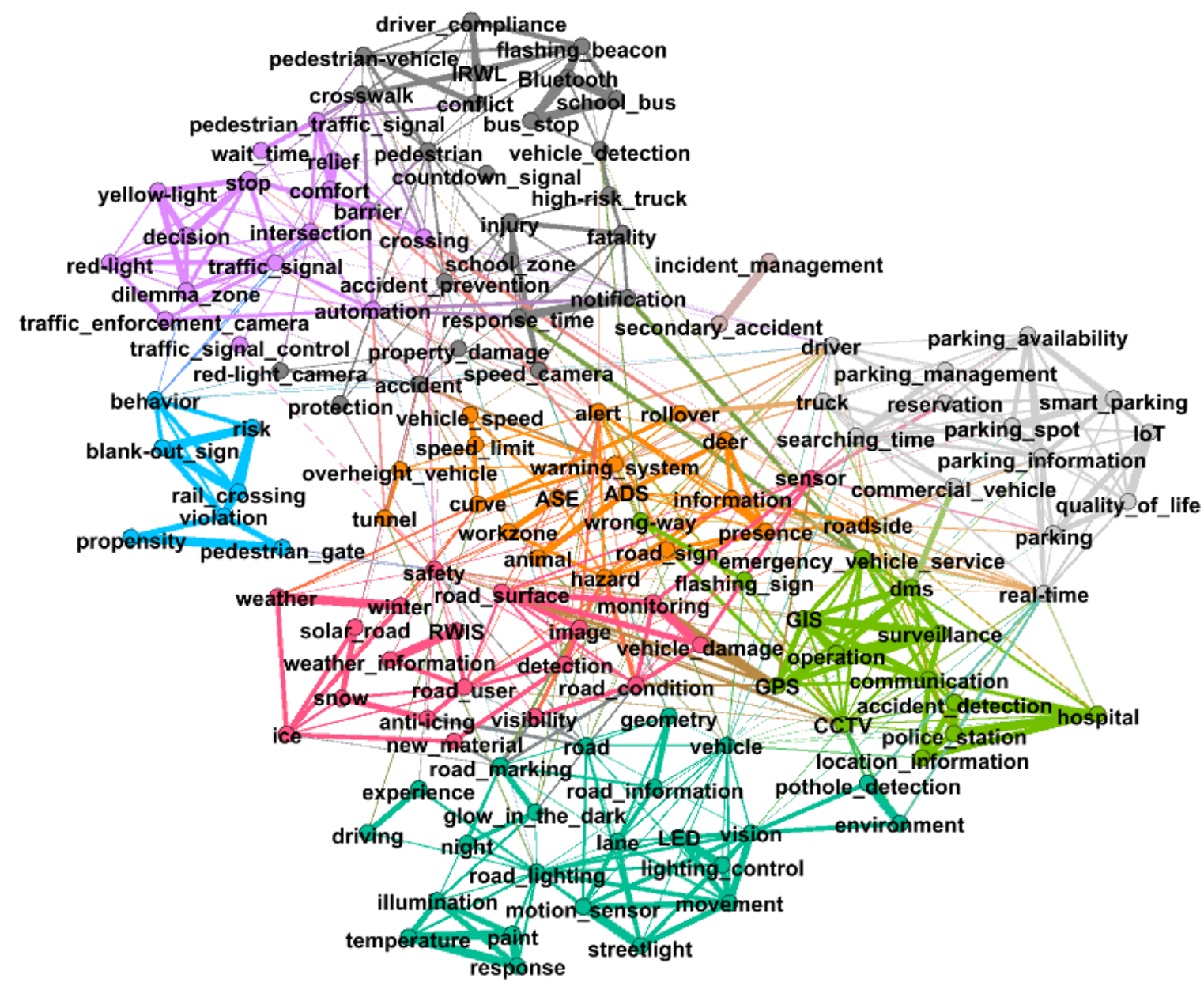

Figure 3.11. Network for the Living Component 


\subsubsection{Phase 3: Hierarchy Table}

\section{Keyword Connotation}

Developing the hierarchy table of indicators and measures connected with the smart city components started from making up the measures through keyword connotation. The keyword connotation primarily focused on the keywords in the same clusters (i.e., target clusters) while the keywords in other clusters but linked to the keywords in the target clusters were supplemented as needed to obtain primitive ideas to phrase immature measures. Then, the measure-oriented discovery search was conducted for additional information to refine the immature measures for completion. For example, the keyword, road marking, at the bottom of the network in Figure 3.7 is directly connected to the keywords such as luminescent paint, charging, and sunlight. The connotation with these keywords led to the primitive measure, road marking using luminescent paints charged by the sunlight. The measure-oriented discovery search found the information, road markings with an intelligent technique like luminescent paints can reduce the use of road lights. Thus, the immature measure was refined to the complete measure, number of reduced road lights by using intelligent road markings. In such a way, all the keywords in the same clusters were connoted to generate the measures for the smart city components. Some clusters produced more than one measure, depending on the number and possible combinations of the keywords in a cluster.

\section{Indicators Development and Hierarchy Table}

The development of the indicators for each smart city component took into account the processes as follows: 1) group the measures from the same clusters, 2) compare the grouped measures across the different clusters to merge when necessary, and 3) create indicators that encompass the grouped measures. Finally, the indicators developed were connected to the smart city components for a hierarchy table. Table 3.2 shows the whole hierarchy table that includes 53 measures in 14 indicators for the five smart city components. 
Table 3.2.Hierarchy Table of Indicators and Measures

\begin{tabular}{|c|c|c|}
\hline Component & Indicator & Measure \\
\hline \multirow[t]{8}{*}{ Environment } & Sustainable Resource & Number of reduced road lights by using intelligent road markings \\
\hline & Management & Reduced electricity consumption of road lights through energy-efficient controls \\
\hline & & Reduced electricity consumption of road lights by using energy-efficient parts \\
\hline & & Energy savings in road tunnels and bridge lighting systems \\
\hline & Renewable energy utilization & Per-vehicle use of renewable energy generated by roadways \\
\hline & & Use of renewable energy generated from roadways for road facilities \\
\hline & & Self-use percentage of renewable energy for roadside facilities \\
\hline & Pollution controls & Reduced fuel consumption per vehicle at traffic signals \\
\hline \multirow[t]{15}{*}{ Mobility } & \multicolumn{2}{|c|}{ Traffic operational performance Reduced waiting time at traffic signals } \\
\hline & \multicolumn{2}{|c|}{ Reduced response time of emergency vehicles } \\
\hline & & Reduced travel time of self-driving vehicles at autonomous lanes \\
\hline & & Reduced traffic delays at toll plazas \\
\hline & & Reduced clearance time at the roads of integrated corridor management \\
\hline & & Increased ratio of average vehicle speed to speed limit at work zones \\
\hline & & Increased throughput time at bottlenecks (e.g., ramps and temporarily closed lanes) \\
\hline & & Volume-to-capacity ratio at work zones \\
\hline & & Delayed travel time on roads in hazardous driving conditions \\
\hline & \multicolumn{2}{|c|}{ Traffic operational performance Reduced travel time at HOV lanes } \\
\hline & $\begin{array}{l}\text { - efficient transport and multi- } \\
\text { modal access }\end{array}$ & Increased throughput time on HOT lanes \\
\hline & Efficient transport and multi- & Increased rates of using shared bike areas at peak hours \\
\hline & modal access & Increased rates of using park and ride facilities \\
\hline & & Public transportation dwell time at traffic signals \\
\hline & & Reduced travel time of commuters through integrated corridor management \\
\hline \multirow[t]{12}{*}{ Governance } & Facility management planning & $\begin{array}{l}\text { Percentage of using road weather information for winter maintenance decision- } \\
\text { making }\end{array}$ \\
\hline & & Percentage of using advanced technologies to improve road inspection data quality \\
\hline & & $\begin{array}{l}\text { Percentage of using advanced technologies to improve bridge inspection data } \\
\text { quality }\end{array}$ \\
\hline & & Efficiency of bureaucracy adopting advanced technologies/materials for pavements \\
\hline & & Efficiency of bureaucracy adopting advanced technologies/materials for bridges \\
\hline & & Managerial efficiency for road facilities security \\
\hline & Emergency operations plan & Efficiency of evacuation planning to respond to disasters \\
\hline & & Efficiency of road resilience planning to respond to disasters \\
\hline & & Extent of integrated controls of services for emergency response \\
\hline & Public and social services & Adoption rate of advanced technologies for smart parking operation \\
\hline & & Administrative efficiency for law enforcement \\
\hline & & Administrative efficiency for law-abiding \\
\hline \multirow[t]{7}{*}{ Economy } & Productivity & Operation cost savings for toll charge/collection services \\
\hline & & Operation cost savings for parking fee charge/collection services \\
\hline & & Cost savings for roadside facilities operations \\
\hline & Efficiency & Cost savings for winter inspection/maintenance \\
\hline & & Cost savings for pavement inspection \\
\hline & & Cost savings for bridge inspection \\
\hline & & Cost savings from road control and maintenance (e.g., rehabilitation and repair) \\
\hline \multirow[t]{10}{*}{ Living } & Accessibility & Satisfaction with access to public parking \\
\hline & Emergency service & Satisfaction with the road operation in accident situations \\
\hline & Safety for road users & $\begin{array}{l}\text { Satisfaction with accident controls at crossing points (e.g., overpass and } \\
\text { underpass) }\end{array}$ \\
\hline & & Satisfaction with incident management to prevent secondary accidents \\
\hline & & Percentage of reduced accidents in hazardous road surface conditions \\
\hline & & Percentage of reduced accidents at traffic signals \\
\hline & & Percentage of reduced accidents by enhancing road visibility conditions \\
\hline & & Comfort level of road users in high-visibility conditions \\
\hline & & $\begin{array}{l}\text { Reduced number of motorized user casualties at accident-prone areas (e.g., curve } \\
\text { and wrong-way) }\end{array}$ \\
\hline & & $\begin{array}{l}\text { Reduced number of non-motorized user casualties at accident-prone areas (e.g., } \\
\text { school zone and crosswalk) }\end{array}$ \\
\hline
\end{tabular}




\subsection{Discussion}

The synthesis for the smart city components derivation identified 37 smart city components (see Figure 3.2) from the existing smart city indexes in Table 2.2. This thesis found that the five components such as environment, mobility, governance, economy, and living are related to urban road innovation in a smart city while others are not. For example, the education/opportunity component is needed to evaluate educational facilities, as the component is related to the effort to enhance the educational level of citizens through educational platforms (Roland Berger, 2019). Furthermore, as urban roads are the evaluation target in this paper, there was no need to consider infrastructure-related components that are required for some smart city indexes to evaluate a smart city as a whole. These components include infrastructure/buildings, waste, and water. The components, such as technology/telecommunication and data, indicate technologies applying for cities so that they were abandoned as I took them as a means to innovate urban roads. However, it should be mentioned that the use of the five selected components does not imply that other components were completely excluded from consideration when developing indicators and measures for urban roads. As a component is included as a part of another component as an indicator (e.g., safety for governance and living, health for living, and policy for governance), this thesis considered the five selected components to be more inclusive of other components. For example, the governance component includes the components such as safety, policy/legal framework, plan/strategy. The living component includes the components such as health/safety and people/citizen/human.

The ROC analysis was used to determine the minimum thresholds of cosine similarities to remove the paired keywords in insignificant relationships. Table 3.3 shows the analysis results generated when the cut-off values (i.e., second column) for the smart city components were estimated. The area under the curve (AUC) refers to the degree of separability and ranges from 0 to 1 (Mandrekar, 2010). As the higher AUCs are preferred, AUC greater than 0.7 is generally considered to indicate that a cut-off value is capable of 
distinguishing between keywords in meaningful and no meaningful relationships. The cut-off values in Table 3.3 are good enough to remove the keywords in insignificant relationships, considering their mean AUCs above 0.7 and the $95 \%$ confidence intervals of the AUCs supported by the p-values. Table 3.3 also includes the additional statistical results, such as positive predictive value (PPV) and negative predictive value (NPV), to show the credibility of the cut-off values. PPV is a percentage that the keywords at a cutoff value or higher are inferred as the binary score of 1 (significant relationship) by human knowledge, while NPV is a percentage that the keywords below a cut-off value are inferred as the binary score of 0 . For example, the probability that I assigned the binary score of 1 to the keywords with the cosine similarity of 0.211 or higher in the environment component is $84.7 \%$. On the other hand, the probability that I indicated no relationship between the keywords that are actually not related to each other by the cosine similarity values is $97.6 \%$. All the statistical results conclude that the cut-off values proper to use as the minimum cosine similarity threshold values to remove the keywords of insignificant relationships to improve the reliability of the data analysis.

Table 3.3. Summary of ROC Analysis

\begin{tabular}{|c|c|c|c|c|c|c|c|c|}
\hline \multirow{2}{*}{ Component } & \multirow{2}{*}{$\begin{array}{l}\text { Cut-off } \\
\text { Value }\end{array}$} & \multirow[t]{2}{*}{$\mathrm{AUC}^{\mathrm{a}}$} & \multirow{2}{*}{$\begin{array}{l}\text { Std. } \\
\text { Error }\end{array}$} & \multicolumn{2}{|c|}{$\begin{array}{l}\text { 95\% Confidence } \\
\text { Interval }\end{array}$} & \multirow[t]{2}{*}{ p-Value } & \multirow[t]{2}{*}{$\mathrm{PPV}^{\mathrm{b}}$} & \multirow[t]{2}{*}{$\mathrm{NPV}^{\mathrm{c}}$} \\
\hline & & & & Lower & Upper & & & \\
\hline Environment & .211 & .928 & .026 & .876 & .979 & $<.001$ & .847 & .976 \\
\hline Mobility & .113 & .858 & .037 & .785 & .930 & $<.001$ & .825 & .814 \\
\hline Governance & .335 & .897 & .034 & .830 & .964 & $<.001$ & .943 & .723 \\
\hline Economy & .360 & .817 & .043 & .734 & .900 & $<.001$ & .823 & .763 \\
\hline Living & .193 & .845 & .040 & .767 & .923 & $<.001$ & .813 & .808 \\
\hline
\end{tabular}

${ }^{\mathrm{a}}$ Area under the curve, ${ }^{\mathrm{b}}$ Positive Predictive Value, ${ }^{\mathrm{c}}$ Negative Predictive Value

The measures in the hierarchy table were developed based on the keywords in the keyword networks. The sources used to generate the networks were the keywords extracted from the main sentences collected through the discovery search. Higher numbers of samples are generally preferred to produce more 
reliable data analysis results. However, Figure 3.3 shows the smaller numbers of the main sentences for some smart city components such as economy and governance compared to others. The limitation of the discovery search to finding such small numbers of sentences can be explained by the lack of raw documents due to relatively little influence and roles of urban roads innovation on a smart city. Nevertheless, it could raise a concern about the reliability of the measures developed for these components. Thus, to maximize the reliability of the measures developed, higher minimum threshold values were required for the smart city components with the lower numbers of the main sentences, which were obtained through the ROC analysis as shown in Figure 3.12 .

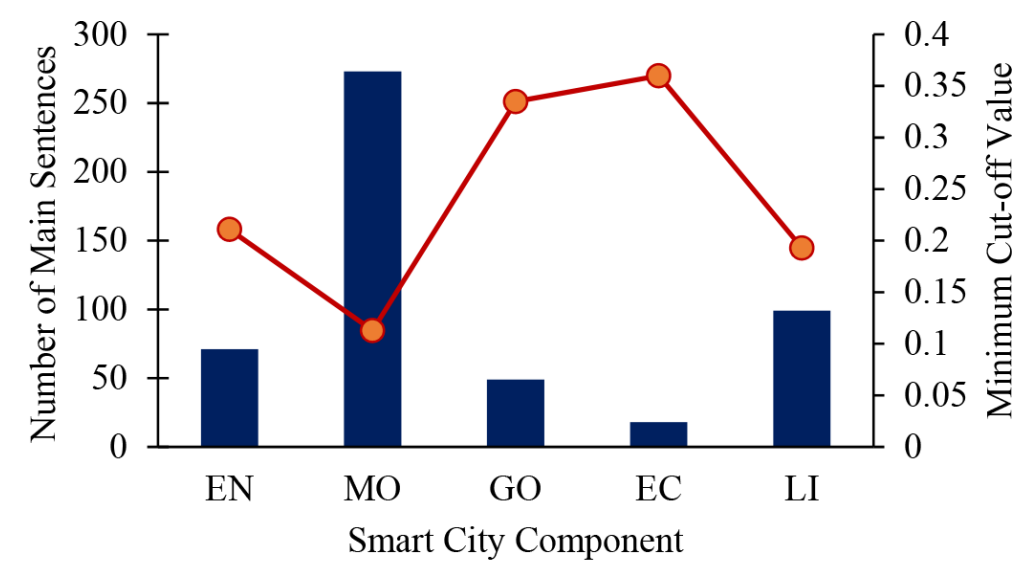

(EN)vironment, (MO)bility, (GO)vernance, (EC)onomy, (LI)ving

Figure 3.12. Numbers of the Sentences and Cut-off Values

The indicator, Traffic operation performance - Efficient transport and multi-modal access, for the mobility component in Table 3.2 includes both attributes of the first and third indicators. The indicator, Traffic operational performance, includes the measures to improve traffic mobility on urban roads. On the other hand, the indicator, Efficient transport and multi-modal access, represents the measures to encourage citizens to use public transportation. While developing the indicators by grouping measures, I found that there are measures that cannot be included in any of the indicators (i.e., first or third indicator) exclusively due to their two-sided attributes belonging to both indicators at the same time. For example, the measures 
recognized as Traffic operation performance-Efficient transport and multi-modal access include Reduced travel time at HOV lanes and Increased throughput time on HOT lanes. The high-occupancy vehicle (HOV) lanes in urban areas are open to vehicles with +2 passengers and transit buses for enhanced traffic mobility and convenience in public transportation use (USDOT, 2015). The high-occupancy toll (HOT) lanes can offer differential pricing strategies, such as free or reduced toll fees for HOVs and full pay access to singleoccupant vehicles, which is also for both traffic mobility and public transportation efficiency (Sas et al., 2007). 


\section{CHAPTER 4: PRIORITIZATION FRAMEWORK FOR ADVANCED SYSTEMS}

This chapter consists of two main subchapters, followed by the subchapter for discussions. The first subchapter presents the overall framework developed to prioritize advanced systems for urban road innovation. The second subchapter shows the demonstration of all the steps in the framework, using the data obtained through a discovery search and created hypothetically.

\subsection{Framework for Advanced System Priority Application}

The framework to prioritize the advanced systems required to innovate urban roads and consequently contribute to smart cities consists of three modules: hierarchy table preparation, input for advanced system information, and advanced system prioritization. Figure 4.1 illustrates these three modules, showing the steps associated with each module as well as the module outputs at the end of the steps. Each module generates its output that in turn plays an essential role as an input for the following module; for example, a hierarchy table from Module 1 to Module 2 and the lifetime cost-effectiveness of advanced systems from Module 2 to Module 3, and the list of advanced systems in priority from Module 3 as a final output for the framework. Each module in detail is presented in the following subsections.

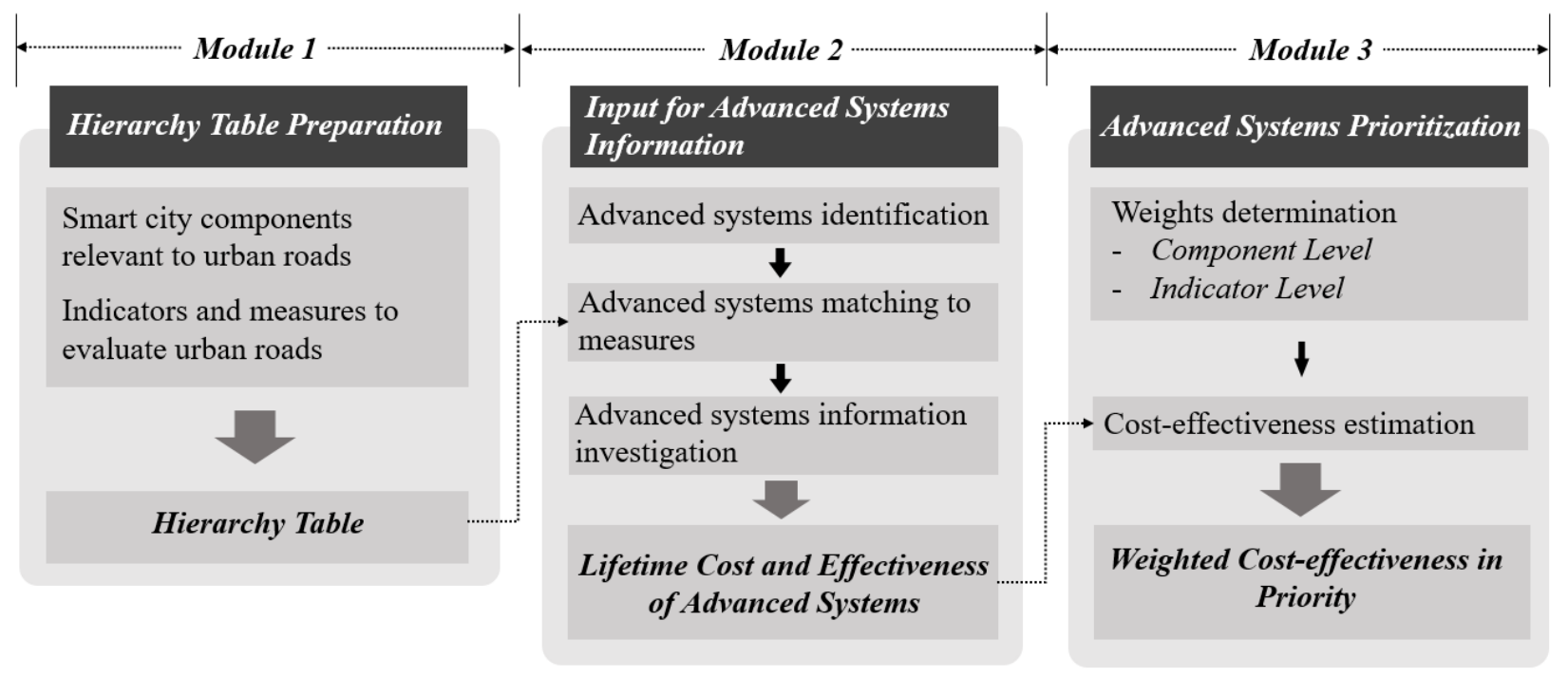

Figure 4.1. Framework to Prioritize Advanced Systems 


\subsubsection{Hierarchy Table Preparation Module}

The purpose of Module 1 is to provide a hierarchy table for Module 2. A hierarchy table is often used to organize elements of parent-child relationships in a simple table format of multiple columns or a hierarchical structure. The hierarchy table in this study includes the elements such as smart city components, indicators, and measures at three different hierarchical levels. This thesis describes the smart city components as the essential service areas for conventional cities to move forward with smartness through the innovative and intelligent development of urban roads. A smart city focuses mainly on the quality of life in people living in city areas by providing all necessary services and resources so that the smart city components generally deal with the topics related to the environment, infrastructure, economy, living, and others. As the services and resources are from urban roads in this thesis, the smart city components need to be specified for urban roads. The indicators and measures under the level of the smart city components work together to evaluate the current development status of urban roads. Each indicator represents a group of measures, and the measures provide standards regarding what benefits (or aspects) from applying advanced systems should be evaluated. Thus, the measures are the basis for data types to be collected. As the measures can be quantitative or qualitative, depending on the attributes of the measures, the identification of measures as quantifiable as possible is preferred to minimize the subjectivity in effectiveness evaluation. The measures also provide perception to match the advanced systems with relevant measures in Module 2. The hierarchy table as an output from Module 1 can be prepared by either way of employing an existing one (if available) or developing a new one. The development of a new hierarchy table generally employs a method such as a text mining technique that analyzes the text data collected from various data sources, synthesis research, or survey for expert opinions.

\subsubsection{Input for Advanced System Information Module}

The input for the advanced systems information module is composed of three tasks: 1) advanced systems identification, 2) advanced systems matching to measures, and 3) advanced systems information investigation. The advanced systems identification task is to generate a list of advanced systems required 
to innovate the performance of urban roads for measures. An extensive discovery search is a primary approach required to identify various advanced systems applicable for urban roads. The discovery search can be implemented in any format, such as online search, surveys, and/or market research, targeting advanced systems commercialized already or in the near future (e.g., within three years), which is important to develop an implementable priority list of the advanced systems. It should be noted that the advanced systems identification task is ahead of the advanced systems matching task for a broad search to explore more systems. Upon completing the discovery search, the identified advanced systems are matched with each measure in the hierarchy table. The matching task considers the usages (e.g., purposes or benefits) designed for an individual advanced system. As a result, matching the advanced systems with the measures produces the three cases as follows:

1) An advanced system is dropped out due to no existence of matching measures.

2) An advanced system is matched with more than one measure due to the multi-usages of the system.

3) A measure has more than one advanced system, resulting from market demands and the maturity of source technologies to develop various advanced systems for the measure.

As the last task in Module 2, the task for advanced systems information investigation seeks the cost and effectiveness information of the matched advanced systems. The cost of an advanced system is a lifetime cost that includes initial installation and operation/maintenance costs. On the other hand, the effectiveness of an advanced system is the estimation of its performance to the matching measure(s). The system effectiveness can be investigated by various methods, depending on the attributes of measures; for example, performance inspection or observation for quantitative measures and public surveys or expert interviews for qualitative measures. It is important that the cost and effectiveness information of advanced systems estimated for the same range (e.g., a whole city or a section of a city) for equal comparisons among them. The cost and effectiveness information of the advanced systems matching measures are the output from Module 2, which becomes the inputs for the advanced systems prioritization in Module 3. Since the 
accuracy of cost and effectiveness information affects the reliability of system priority results in Module 3, multiple data sources need to be considered for cross-checking.

\subsubsection{Advanced System Prioritization Module}

The advanced systems prioritization module starts with determining the weights at the levels of components and indicators each. Then, the cost-effectiveness values of advanced systems at the level of measures are estimated. The application of an advanced system for an urban road aims to contribute an indicator to a smart city component by enhancing a matching measure of the advanced system. A city has different demands on its smart city components, and the indicators under each component have different impacts on the component. Thus, the weights at the component and indicator levels are applied to the costeffectiveness values of advanced systems for weighted cost-effectiveness, which is formulated in Equation 4.1.

$$
C E_{m / i / c}^{\prime}(s)=C E_{m / i / c}(s) \times w_{i / c} \times w_{c}
$$

where, $w_{c}$ is a weight of smart city component $c, \sum_{c=1}^{p} w_{c}=1$ for a total of $p$ components; $w_{i / c}$ is a weight of indicator $i$ under smart city component $c, \sum_{i=1}^{q} w_{i / c}=1$ for a total of $q$ indicators; $C E_{m / / c}(s)$ is the costeffectiveness of an advanced system $s$ matched with measure $m$ under indicator $i$ and smart city component $c$; and $C E_{m / i / c}^{\prime}(s)$ is a weighted $C E_{\mathrm{m} / \mathrm{i} / \mathrm{c}}(\mathrm{s})$.

The weights at the component and indicator levels can be determined by either approach as follows:

- Relative contributions among components (or indicators) to a smart city (or a component associated with the indicators)

- Different demands for components (or indicators), estimated from the current development status of urban roads in terms of measures 
The use of an appropriate weight determination method depends on what approaches (e.g., relative contributions or different demands) are considered for the weights of components and indicators. For example, the component or indicator weights based on relative contributions can employ a pairwise comparison method such as an analytic hierarchy process (AHP), analytic network process (ANP), ELECTRE, majority election, and PROMETHEE (Yoon et al., 2017). On the other hand, the component and indicator weights based on different demands can be estimated by taking the steps as follows:

1) Set a target (T), baseline (BL), and current development status (CDS) for each measure. The target is set at a value that a measure is ultimately achieved based on urban road management policy or strategy. The baseline was an initial value regarding the measure when the development of an urban road was considered to enhance the measure for the first time. It should be noted that the first year for the baseline can be this year if the urban road development starts now. The current development status is the value that an urban road represents the performance regarding the measure at the present time.

2) Calculate percent current achievement (\%CA), as seen in Equation 4.2. The Abs() function returns the absolute values of the given formulas so that Equation 4.2 can be applied for measure targets seeking both larger and smaller values.

$$
\% C A=\frac{A b s(C D S-B L)}{A b s(T-B L)} \times 100(\%)
$$

3) Get an average \%CA of the measure(s) at each indicator.

4) Subtract the average $\% C A(a v g . \% C A)$ from $100 \%$ for an average percent demand $(A v g . \% D)$ for each indicator.

$$
\text { Avg. } \% D=100 \%-A v g . \% C A
$$

Equation 4.3 
5) For indicator weights, normalize the Avg. \%D values of the indicators at each smart city component. When the average percent demand of indicator $i(=1,2, \ldots, q)$ in smart city component $c$ is denoted as $A v g . \% D_{i / c}$, the indicator weight can be estimated by Equation 4.4:

$$
w_{i / c}=\frac{A v g . \% D_{i / c}}{\sum_{i=1}^{q} \operatorname{Avg} \cdot \% D_{i / c}}
$$

6) For component weights, get an average of the Avg. \%D values of the indicators at each smart city component, then normalize the component average percent demands. The average percent demand of component $c\left(=A v g . \% D_{c}\right)$ can be obtained by Equation 4.5. Then, the weight of component $c$ $(=1,2, \ldots, p)$ is derived from Equation 4.6.

$$
\begin{gathered}
\text { Avg. } \% D_{c}=\frac{\sum_{i=1}^{n} A v g . \% D_{i / c}}{q} \\
w_{c}=\frac{A v g . \% D_{c}}{\sum_{c=1}^{p} A v g . \% D_{c}}
\end{gathered}
$$

Table 4.1 presents a hypothetical hierarchy table to exemplify the process of estimating the weights of smart city components and indicators. It assumes that there are two smart city components, A and B, and the associated indicators (e.g., three indicators in A and two indicators in B). The measures of A1 are specified to demonstrate Steps 1) and 2), while other measures are labeled by their parent component and indicator names along with the ordinal numbers. The measures of A1 are set by target, baseline, and current development status values. The development status for the first and second measures is higher the better, while the third measure is the opposite. By using Equation 4.2, the percent current achievement of the first measure is: 


$$
\% C A=\frac{A b s(12-0)}{A b s(20-0)} \times 100(\%)=60.0 \%
$$

Similarly, the $\% C A$ values for the second and third measures are $33.3 \%$ and $44.4 \%$, respectively.

Table 4.1. Example of a Hierarchy Table for Component and Indicator Weights

\begin{tabular}{|c|c|c|c|c|c|c|}
\hline Component & Indicator & Measure & Unit & $\mathrm{T}$ & BL & CDS \\
\hline \multirow[t]{7}{*}{$\mathrm{A}$} & A1 & Reduced waiting time at traffic signals & $\mathrm{Sec}$ & 20 & 0 & 12 \\
\hline & & $\begin{array}{l}\text { Increased ratio of average vehicle speed } \\
\text { to speed limit at work zones }\end{array}$ & - & 1.0 & 0.4 & 0.6 \\
\hline & & $\begin{array}{l}\text { Delayed travel time on roads in } \\
\text { hazardous driving conditions }\end{array}$ & Min & 0 & 27 & 15 \\
\hline & $\mathrm{A} 2$ & A2-M1 & & & & \\
\hline & & A2-M2 & & & & \\
\hline & & A2-M3 & & & & \\
\hline & A3 & A3-M1 & & & & \\
\hline \multirow[t]{5}{*}{ B } & B1 & B1-M1 & & & & \\
\hline & & $\mathrm{B} 1-\mathrm{M} 2$ & & & & \\
\hline & & B1-M3 & & & & \\
\hline & B2 & B2-M1 & & & & \\
\hline & & B2-M2 & & & & \\
\hline
\end{tabular}

The $\% C A$ values of the three specified measures are presented in Table 4.2 that also shows the $\% C A$ values randomly generated for other measures. The last three columns in Table 4.2 are the results of Steps 3), 4), and 6) (but by applying Equation 4.5 only in Steps 6)). Then, the weights of the indicators at each component can be estimated by applying Equation 4.4 in Step 5). For example, the indicator weights for smart city component A are:

$$
\begin{aligned}
& w_{1 / A}=\frac{54.1 \%}{54.1 \%+54.4 \%+96.2 \%}=0.264 \\
& w_{1 / A}=\frac{54.4 \%}{54.1 \%+54.4 \%+96.2 \%}=0.266
\end{aligned}
$$




$$
w_{1 / A}=\frac{96.2 \%}{54.1 \%+54.4 \%+96.2 \%}=0.470
$$

Similarly, the component weights by applying Equation 4.6 in Step 6) are:

$$
\begin{aligned}
& w_{A}=\frac{68.2 \%}{68.2 \%+39.3 \%}=0.634 \\
& w_{B}=\frac{39.3 \%}{68.2 \%+39.3 \%}=0.366
\end{aligned}
$$

\begin{tabular}{|c|c|c|c|c|c|c|}
\hline $\begin{array}{l}\text { Smart City } \\
\text { Component }\end{array}$ & Indicator & Measure & $\% C A$ & $\begin{array}{l}A v g . \\
\% C A_{i / c}\end{array}$ & $\begin{array}{l}A v g \\
\% D_{i / c}\end{array}$ & $\begin{array}{l}A v g . \\
\% D_{c}\end{array}$ \\
\hline \multirow[t]{7}{*}{ A } & A1 & Reduced waiting time at traffic signals & $60.0 \%$ & $45.9 \%$ & $54.1 \%$ & $68.2 \%$ \\
\hline & & $\begin{array}{l}\text { Increased ratio of average vehicle speed } \\
\text { to speed limit at work zones }\end{array}$ & $33.3 \%$ & & & \\
\hline & & $\begin{array}{l}\text { Delayed travel time on roads in hazardous } \\
\text { driving conditions }\end{array}$ & $44.4 \%$ & & & \\
\hline & $\mathrm{A} 2$ & A2-M1 & $43.9 \%$ & $45.6 \%$ & $54.4 \%$ & \\
\hline & & A2-M2 & $29.9 \%$ & & & \\
\hline & & A2-M3 & $63.0 \%$ & & & \\
\hline & A3 & A3-M1 & $3.8 \%$ & $3.8 \%$ & $96.2 \%$ & \\
\hline \multirow[t]{5}{*}{ B } & B1 & B1-M1 & $11.9 \%$ & $59.3 \%$ & $40.7 \%$ & $39.3 \%$ \\
\hline & & B1-M2 & $91.4 \%$ & & & \\
\hline & & B1-M3 & $74.7 \%$ & & & \\
\hline & B2 & B2-M1 & $42.7 \%$ & $62.1 \%$ & $37.9 \%$ & \\
\hline & & B2-M2 & $81.5 \%$ & & & \\
\hline
\end{tabular}

Table 4.2. Example of \%Current Achievement and \%Demand Value Calculations

The effectiveness of an advanced system is estimated in terms of its matching measure. It implies that the units and scales of the system effectiveness could be variant according to measures. For example, assuming that each of the specified measures in Table 4.1 is assigned by one advanced system, the three systems for the measures from top to bottom are estimated as the units of reduced time, increased ratio, and 
delayed travel time. Also, the scales for the effectiveness of the advanced systems matching with the first and third measures are the time units in seconds and minutes, respectively. Thus, the normalization of system effectiveness value is required. The normalization can be done by converting them into contribution ratios at each indicator, as seen in Equation 4.7 and Equation 4.8. Equation 4.7 is applied to measure targets pursuing higher values, whereas Equation 4.8 is for measure targets pursuing lower values.

$$
\begin{gathered}
C R=\frac{\text { Effectiveness }}{A b s(T-C D S)} \\
C R=1-\frac{\text { Effectiveness }}{A b s(T-C D S)}
\end{gathered}
$$

Equation 4.8

Table 4.3 shows the contribution ratios of the advanced systems for measures A1-M1 and A1-M3 from Table 4.1. For example, the contribution ratio $(C R)$ of the advanced system, A1-M1-S1, is:

$$
C R=\frac{7}{A b s(20-12)}=0.875
$$

The $C R$ of the advanced system, A1-M3-S1, is:

$$
C R=1-\frac{12}{A b s(0-15)}=0.200
$$


Table 4.3. Contribution Ratios of Advanced System Effectiveness

\begin{tabular}{|c|c|c|c|c|}
\hline Measure & $\begin{array}{l}\text { Matching } \\
\text { System }\end{array}$ & Effectivenes & & $C R$ \\
\hline \multirow{3}{*}{$\begin{array}{l}\text { (A1-M1) Reduced waiting time at } \\
\text { traffic signals }\end{array}$} & A1-M1-S1 & \multirow{3}{*}{$\begin{array}{l}\text { Reduced waiting time } \\
\qquad(\mathrm{sec})\end{array}$} & 7 & 0.875 \\
\hline & A1-M1-S2 & & 4 & 0.500 \\
\hline & A1-M1-S3 & & 6 & 0.750 \\
\hline \multirow{4}{*}{$\begin{array}{l}\text { (A1-M3) Delayed travel time on } \\
\text { roads in hazardous driving } \\
\text { conditions }\end{array}$} & A1-M3-S1 & \multirow{4}{*}{$\begin{array}{l}\text { Delayed travel time } \\
\text { (min) }\end{array}$} & 12 & 0.200 \\
\hline & $\mathrm{A} 1-\mathrm{M} 3-\mathrm{S} 2$ & & 9 & 0.400 \\
\hline & A1-M3-S3 & & 10 & 0.333 \\
\hline & A1-M3-S4 & & 6 & 0.600 \\
\hline
\end{tabular}

As the actual effectiveness values of advanced systems are transformed into contribution ratios that range from 0 to 1 , system lifetime costs also need to be adjusted using a normalization technique to make distinctive comparisons. The advanced systems to be included for cost normalization vary based on the purposes of advanced systems prioritizing: for example, advanced system priorities for each component or across components as a whole. Finally, the normalized cost-effectiveness of an advanced system is applied to Equation 4.1 for weighted cost-effectiveness, which is repeated for all other advanced systems to generate a whole priority list. If any advanced systems contribute to more than one measure, all the weighted costeffectiveness values of the systems across the measures are combined for ranking.

\subsection{Application of Advanced System Prioritization Framework}

\subsubsection{Module-1: Hierarchy Table Preparation}

The hierarchy table applied to demonstrate the advanced system prioritization framework was presented in Table 3.2. The measures at the lowest level in the hierarchy table provide information on advanced systems required to enhance the current development status of urban roads. 


\subsubsection{Module-2: Input for Advanced System Information}

A list of advanced systems applicable to enhance urban roads regarding the measures in a hierarchy table was compiled by a discovery search using the searching keywords such as intelligent transportation system (ITS), smart highway system, smart roads, and intelligent highway system. The identification of advanced systems came up with a basic information search (e.g., benefits and contributions) that was utilized to match them with each measure in the hierarchy table. It should be noted that the discovery search focused on identifying the advanced systems for a few selected components, indicators, and measures, considering sufficiency to demonstrate the whole prioritization framework. Given the consideration, this thesis identified 15 advanced systems matching with the selected measures. The identified advanced systems took an in-depth investigation for their lifetime costs and effectiveness. The primary data source for the in-depth investigation was the USDOT ITS Deployment Evaluation Database available at: https://www.itskrs.its.dot.gov/. A comprehensive online search was also accompanied to supplement the investigation task.

Table 4.4 shows the advanced systems for the selected components, indicators, and measures in the hierarchy table and their costs and effectiveness within a city boundary. Some of the advanced systems found more than one measure matching due to their versatilities; for example, intelligent road marking for A1-M1 and A1-M2 and adaptive traffic signal control system for A3-M1 and B1-M1. As there was a limitation to find exact lifetime costs and effectiveness values for all the advanced systems from open sources, pseudo-data were used for the advanced systems whose lifetime costs and/or effectiveness values were not available. However, the random generation for lifetime costs and effectiveness values was constrained by reasonable cost and effectiveness ranges inferred from other similar advanced systems to make the prioritization procedures plausible. 
Table 4.4. Example of Advanced Systems Matching to Measures with Cost and Effectiveness

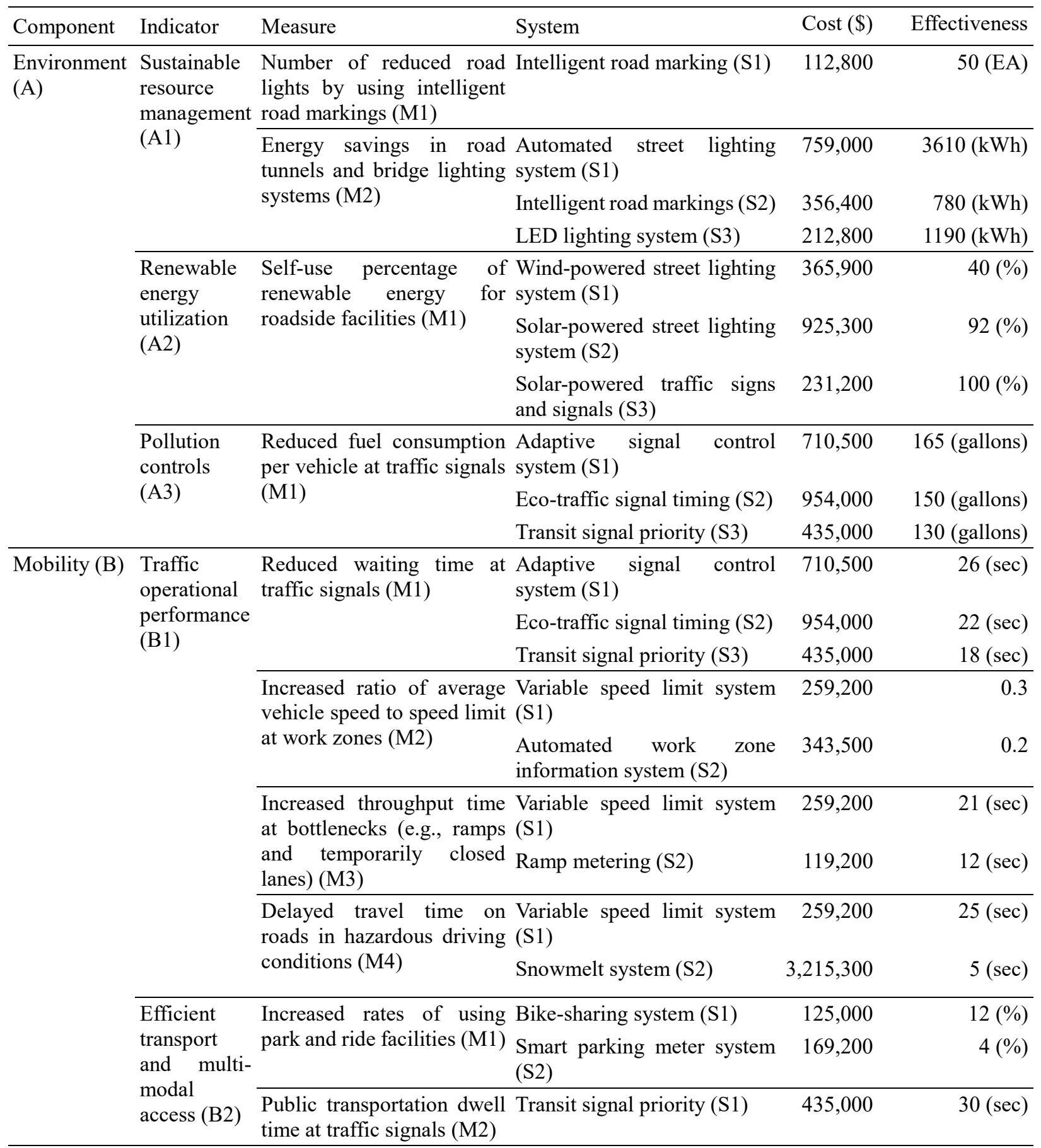




\subsubsection{Module-3: Advanced System Prioritization}

The prioritization of the advanced systems first needed to determine the weights of the components and indicators each in Table 4.4. The weights determination went through Equation 4.2 - Equation 4.6 that required setting three input variables, such as the target $(T)$, baseline $(B L)$, and current development status $(C D S)$ for each measure. However, the actual values for these three variables for the advanced systems were not available, so that they should be assumed. Table 4.5 shows the values of these variables hypothetically produced for the advanced systems. For example, for the A1-M1 measure, Number of reduced road lights by using intelligent road markings, it assumed that the $T$ value was the goal that a local government set to achieve after completion of a short-term smart city project. The $B L$ value represented the number of road lights reduced at the beginning of the project, which was zero because nothing was achieved. The $C D S$ value indicates that the ongoing project now has achieved to reduce road lights by two by applying intelligent road markings. As another example, it assumed that a local government made a plan to improve the measure B2-M2, Public transportation dwell time at traffic signals, and set all the intersections within the city boundary as a project target, so the dwell time was an average dwell time of all city intersection. The $T, B L$, and $C D S$ values were assumed to be 80,180 , and 130 seconds, in the end, beginning, and presence of the project, respectively.

Table 4.5. The T, BL, and CDS Values Assumed for each Measure

\begin{tabular}{ccccccc}
\hline Component & Indicator & Measure & Unit & $T$ & $B L$ & $C D S$ \\
\hline \multirow{4}{*}{$\mathrm{A}$} & \multirow{2}{*}{$\mathrm{A} 1$} & $\mathrm{M} 1$ & $\mathrm{EA}$ & 100 & 0 & 20 \\
& & $\mathrm{M} 2$ & $\mathrm{kWh}$ & 20,000 & 10,000 & 12,000 \\
\cline { 2 - 7 } & $\mathrm{A} 2$ & $\mathrm{M} 1$ & $\%$ & 100 & 10 & 40 \\
\cline { 2 - 7 } & $\mathrm{A} 3$ & $\mathrm{M} 1$ & Gallon & 400 & 0 & 200 \\
\hline \multirow{4}{*}{$\mathrm{B}$} & & $\mathrm{M} 1$ & $\mathrm{Sec}$ & 60 & 0 & 20 \\
& \multirow{2}{*}{$\mathrm{B} 1$} & $\mathrm{M} 2$ & - & 0.5 & 0 & 0.125 \\
& & $\mathrm{M} 3$ & $\mathrm{Sec}$ & 30 & 0 & 5 \\
& & $\mathrm{M} 4$ & $\mathrm{Sec}$ & 0 & 60 & 40 \\
\hline & \multirow{2}{*}{$\mathrm{B} 2$} & $\mathrm{M} 1$ & $\%$ & 30 & 0 & 5 \\
& & $\mathrm{M} 2$ & $\mathrm{Sec}$ & 80 & 180 & 130 \\
\hline
\end{tabular}


The $T, B L$, and $C D S$ values for the advanced systems were processed to the percentages of current achievement $\% C A s$ for the measures and the average percent demands $(A v g . \% D)$ for the indicators using Equation 4.2 and Equation 4.3. Then, the processed values were estimated to the weights for the selected smart city components and indicators. Table 4.6 shows the result of all the processed values. The estimation procedures for the processed values were avoided in this section, as the details are already presented in the previous framework chapter.

Table 4.6. Result of the Weight Determination

\begin{tabular}{|c|c|c|c|c|c|c|}
\hline $\begin{array}{l}\text { Component } \\
\text { (Weight) }\end{array}$ & $\begin{array}{l}\text { Indicator } \\
\text { (Weight) }\end{array}$ & Measure & $\% C A$ & $\begin{array}{l}A v g . \\
\% C A_{i / c}\end{array}$ & $\begin{array}{l}A v g . \\
\% D_{i / c}\end{array}$ & $\begin{array}{l}A v g . \\
\% D_{c}\end{array}$ \\
\hline \multirow{4}{*}{$\mathrm{A}(0.48)$} & \multirow{2}{*}{ A1 $(0.41)$} & M1 & $20.0 \%$ & \multirow{2}{*}{$20.0 \%$} & \multirow{2}{*}{$80.0 \%$} & \multirow{4}{*}{$65.6 \%$} \\
\hline & & M2 & $20.0 \%$ & & & \\
\hline & A2 (0.34) & M1 & $33.3 \%$ & $33.3 \%$ & $66.7 \%$ & \\
\hline & A3 $(0.25)$ & M1 & $50.0 \%$ & $50.0 \%$ & $50.0 \%$ & \\
\hline \multirow{6}{*}{$\mathrm{B}(0.52)$} & \multirow{4}{*}{ B1 (0.52) } & M1 & $33.3 \%$ & \multirow{4}{*}{$27.1 \%$} & \multirow{4}{*}{$72.9 \%$} & \multirow{6}{*}{$69.8 \%$} \\
\hline & & M2 & $25.0 \%$ & & & \\
\hline & & M3 & $16.7 \%$ & & & \\
\hline & & M4 & $33.3 \%$ & & & \\
\hline & \multirow{2}{*}{ B2 (0.48) } & M1 & $16.7 \%$ & \multirow{2}{*}{$33.3 \%$} & \multirow{2}{*}{$66.7 \%$} & \\
\hline & & M2 & $50.0 \%$ & & & \\
\hline
\end{tabular}

The weighted cost-effectiveness calculation for the advanced systems first conducted normalization for the effectiveness values in different units and scales. All the effectiveness values of the advanced systems were converted into the contribution ratios, applying Equation 4.7 and Equation 4.8. However, the conversion procedures to normalize the effectiveness values were avoided as they were already presented in the previous framework chapter. The effectiveness values in the contribution ratios of 0 to 1 needed the lifetime costs to scale down for distinctive comparison. There exist various normalization methods such as min-max, z-score, and logarithmic scaling. The min-max method is commonly used to normalize values into a range of 0 to 1 , where a maximum value being 1 and a minimum value being 0 . Thus, this method is not applicable for a prioritization problem based on cost-effectiveness values as there is always the case 
assigning 0 to a denominator. The Z-score method normalizes values using the arithmetic mean and standard deviation of given values. It indicates that values getting closer to the mean converge to zero, which produces cost-effectiveness values being exponential. On the other hand, the logarithmic scaling method compresses a wide range of values into a low range, depending on a base number used, and does not skew the raw values in normalization. Hence, the logarithmic scaling method was used to normalize the lifetime costs of the advanced systems, using Equation 4.9, where $N C$ is the normalized lifetime cost of an advanced system.

$$
N C=\log (\text { Cost })
$$

Equation 4.9

Once both raw effectiveness values and lifetime costs were standardized, the cost-effectiveness was calculated by dividing the contribution ratios by the normalized lifetime costs. Then, the weights of the smart city components and indicators were multiplied by the weighted CEs. For example, the costeffectiveness $(C E)$ of the advanced system, A1-M1-S1, was estimated by Equation 4.10.

$$
C E=\frac{0.63}{5.052}=0.124
$$

By applying the weights of the component $(=0.48)$ and indicator (i.e., 0.48 and 0.41 , respectively; see Table 4.6), where this advanced system included, the weighted CE was:

$$
\text { Weighted } C E=0.124 \times 0.48 \times 0.41=0.024
$$


Table 4.7 shows the CE and weighted CE values of the advanced systems. However, it should be mentioned that the weighted CE values in Table 4.7 did not represent some advanced systems, such as variable speed limit system, transit signal priority, adaptive signal control system, intelligent road marking, and eco-traffic signal timing, contributing to more than one measure. Therefore, the weighted CE values for those were summed so that the priorities of the advanced systems were finalized as shown in Table 4.8. In this hypothetical example, the prioritization framework recognized the variable speed limit system as the most cost-effective advanced system for investment.

Table 4.7. CE and Weighted CE Results for the Advanced Systems

\begin{tabular}{ccccccc}
\hline System label & $\mathrm{E}$ & $\mathrm{CR}$ & Cost & $\mathrm{NC}$ & $\mathrm{CE}$ & Weighted CE \\
\hline A1-M1-S1 & 50 & 0.63 & 112,800 & 5.052 & 0.124 & 0.024 \\
A1-M2-S1 & 3,610 & 0.45 & 759,000 & 5.880 & 0.077 & 0.015 \\
A1-M2-S2 & 780 & 0.10 & 356,400 & 5.552 & 0.018 & 0.003 \\
A1-M2-S3 & 1,190 & 0.15 & 212,800 & 5.328 & 0.028 & 0.005 \\
A2-M1-S1 & 40 & 0.67 & 365,900 & 5.563 & 0.120 & 0.020 \\
A2-M1-S2 & 92 & 1.00 & 925,300 & 5.966 & 0.168 & 0.027 \\
A2-M1-S3 & 100 & 1.00 & 231,200 & 5.364 & 0.186 & 0.030 \\
A3-M1-S1 & 165 & 0.83 & 710,500 & 5.852 & 0.141 & 0.017 \\
A3-M1-S2 & 150 & 0.75 & 954,000 & 5.980 & 0.125 & 0.015 \\
A3-M1-S3 & 130 & 0.65 & 435,000 & 5.638 & 0.115 & 0.014 \\
B1-M1-S1 & 26 & 0.65 & 710,500 & 5.852 & 0.111 & 0.030 \\
B1-M1-S2 & 22 & 0.55 & 954,000 & 5.980 & 0.092 & 0.025 \\
B1-M1-S3 & 18 & 0.45 & 435,000 & 5.638 & 0.080 & 0.022 \\
B1-M2-S1 & 0.3 & 0.80 & 259,200 & 5.414 & 0.148 & 0.040 \\
B1-M2-S2 & 0.2 & 0.53 & 343,500 & 5.536 & 0.096 & 0.026 \\
B1-M3-S1 & 21 & 0.84 & 259,200 & 5.414 & 0.155 & 0.042 \\
B1-M3-S2 & 12 & 0.48 & 119,200 & 5.076 & 0.095 & 0.026 \\
B1-M4-S1 & 25 & 0.38 & 259,200 & 5.414 & 0.069 & 0.019 \\
B1-M4-S2 & 5 & 0.88 & $3,215,300$ & 6.507 & 0.134 & 0.036 \\
B2-M1-S1 & 12 & 0.48 & 125,000 & 5.097 & 0.094 & 0.024 \\
B2-M1-S2 & 4 & 0.16 & 169,200 & 5.228 & 0.031 & 0.008 \\
B2-M2-S1 & 30 & 0.4 & 435,000 & 5.638 & 0.071 & 0.018 \\
\hline E: Effectiveness & $C R: C 0 n t 7 i b 40 n$ & $N C: N 07 m a 17$ &
\end{tabular}

E: Effectiveness, CR: Contribution, NC: Normalized Cost, CE: Cost-Effectiveness 
Table 4.8. Result of Advanced Systems Prioritization

\begin{tabular}{|c|c|c|c|}
\hline Priority & System Name & System Label & Total weighted CE \\
\hline \multirow[t]{3}{*}{1} & Variable speed limit system & B1-M2-S1 & 0.101 \\
\hline & & B1-M3-S1 & \\
\hline & & B1-M4-S1 & \\
\hline \multirow[t]{3}{*}{2} & Transit signal priority & A3-M1-S3 & 0.053 \\
\hline & & B1-M1-S3 & \\
\hline & & B2-M2-S1 & \\
\hline \multirow[t]{2}{*}{3} & Adaptive signal control system & A3-M1-S1 & 0.047 \\
\hline & & B1-M1-S1 & \\
\hline \multirow[t]{2}{*}{4} & Eco-traffic signal timing & A3-M1-S2 & 0.040 \\
\hline & & B1-M1-S2 & \\
\hline 5 & Snowmelt system & B1-M4-S2 & 0.036 \\
\hline 6 & Solar-powered traffic signs and signals & A2-M1-S3 & 0.030 \\
\hline \multirow[t]{2}{*}{7} & Intelligent road marking & A1-M1-S1 & 0.028 \\
\hline & & $\mathrm{A} 1-\mathrm{M} 2-\mathrm{S} 2$ & \\
\hline 8 & Solar-powered street lighting system & A2-M1-S2 & 0.027 \\
\hline 9 & $\begin{array}{l}\text { Automated work zone information } \\
\text { system }\end{array}$ & B1-M2-S2 & 0.026 \\
\hline 10 & Ramp metering & B1-M3-S2 & 0.026 \\
\hline 11 & Bike-sharing system & B2-M1-S1 & 0.024 \\
\hline 12 & Wind-powered street lighting system & A2-M1-S1 & 0.020 \\
\hline 13 & Automated street lighting system & A1-M2-S1 & 0.015 \\
\hline 14 & Smart parking meter system & B2-M1-S2 & 0.008 \\
\hline 15 & LED lighting system & A1-M2-S3 & 0.005 \\
\hline
\end{tabular}

\subsubsection{Discussions on the Application Procedures and Result}

The application of the system prioritization framework demonstrated the entire procedures following the three modules and the associated steps in Figure 4.1. All the steps in each module were elaborated using the hypothetical examples to conclude the priority result in Table 4.8. However, the application of the presented prioritization framework might encounter two possible cases that were not fully explained while demonstrating the framework. Thus, these two cases are discussed in this section as follows. 


\section{Case-1: 100\% Current Achievement (i.e., \%CA=100\%) at a Measure}

This case occurs when the current achievement percentage of a measure is $100 \%$, indicating that the measure had met its measure target in the past. There can be three possible scenarios in this case, as presented in Figure 4.2 which also shows all the measures on progress (i.e., not 100\% current achievement) toward their targets. The three scenarios are: Scenario $1-\mathrm{a} \% C A$ of $100 \%$ for one or more (but not all) measure(s) in one indicator (see Figure 4.2(b)), Scenario 2 - a $\% C A$ of $100 \%$ for all measures in one indicator (see Figure 4.2(c)), and Scenario 3-a $\% C A$ of 100 for all measures in one smart city component (see Figure $4.2(\mathrm{~d})$ ). The $100 \%$ current achievement of a measure is interpreted as $0 \%$ demand on new investment in advanced systems, so it lowers the weights of a component and indicator to which the measure belongs. The second scenario of this case makes the weight of the indicator zero (see Figure 4.2(c)). Similarly, the component weight in the third scenario becomes zero (see Figure 4.2(d)). The application of the prioritization framework for this case can consider two options for a $100 \%$ measure. One option is to set a new target for the $100 \%$ measure that is certainly higher than the current target so that the investment priorities in the indicator and component of this measure are not discouraged. However, one should contemplate that this option might cause unequal development in other indicators or components. The other option is to keep the $100 \%$ measure with no change in its target so that other indicators or components can be given to higher investment demands for balanced development across indicators and components in a smart city. For example, the transitions from Figure 4.2(a) to Figure 4.2(b) to Figure 4.2(c) show the increasing weights in other indicators (e.g., A2 and A3) in the selection of the second option. As a result, all the indicators and components can equally meet their targets. However, if the \%CAs of ongoing measures are far behind the $100 \%$ measure requiring a longer period of time to reach their targets, one might consider them with certain tentative targets at which a new target of the $100 \%$ measure is set to prevent it from getting outdated. 


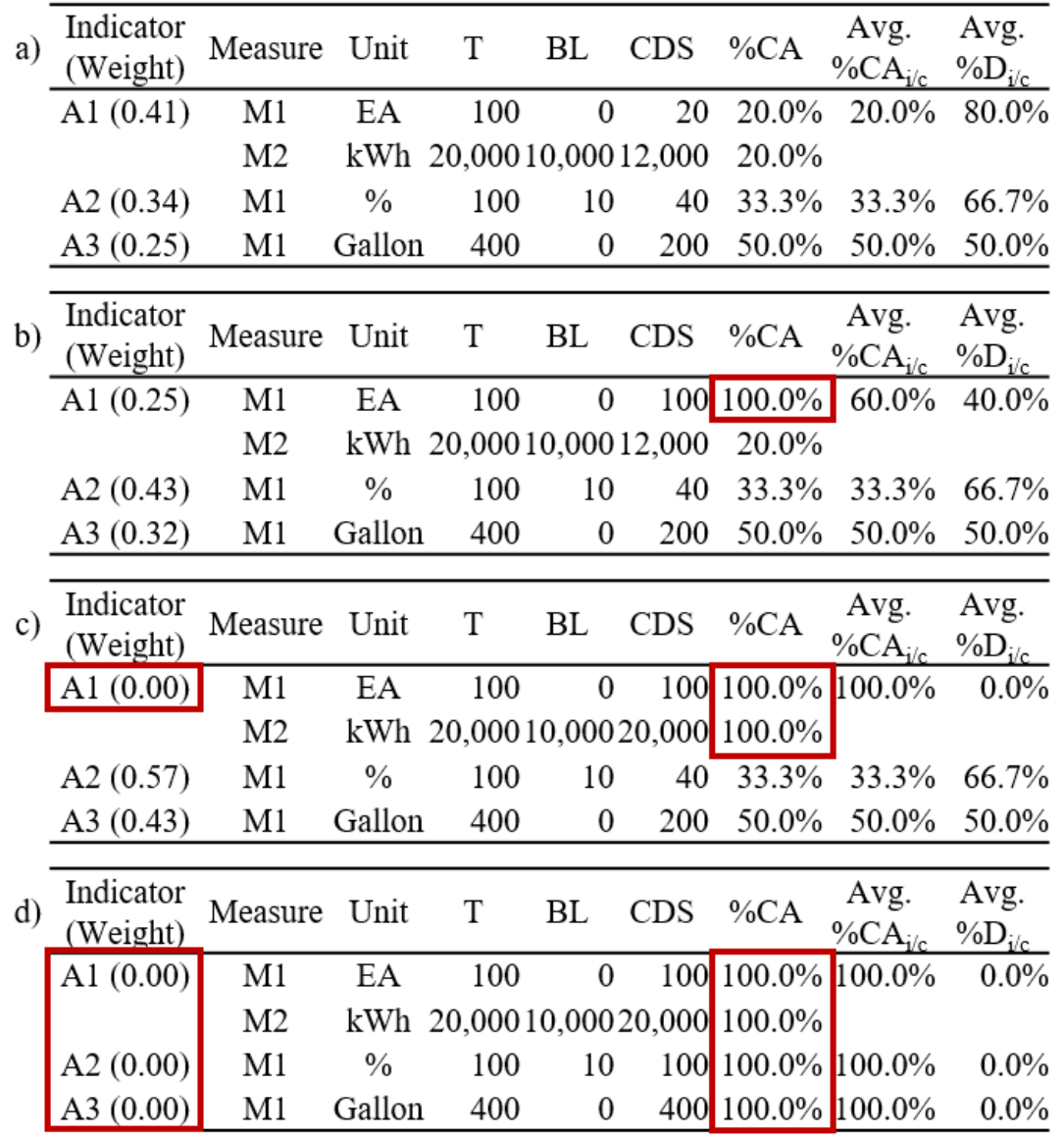

Figure 4.2. Possible Scenarios in Case-1: a) all measures on progress, b) scenario 1, c) scenario 2, and d) scenario 3

\section{Case-2: Effectiveness of an Advanced System exceeding a Measure Target}

This case happens when the effectiveness of an advanced system exceeds the remaining demand (i.e., the difference between a target and current development status) of a measure. Thus, the contribution ratio of this advanced system is larger than one by Equation 4.7 or Equation 4.8. For example, Table 4.5 indicates that the self-use percentage of renewable energy for roadways facilities is currently $40 \%$ in a smart city when the target is $100 \%$ (see M1 of A1 in Table 4.5). The advanced system, solar-powered street lighting system (A2-M1-S2 in Table 4.4), is expected to add the additional renewable energy use of $92 \%$ to the current development status, $40 \%$. The effectiveness of the advanced system makes the measure beyond the target, which results in its contribution ratio estimated at $1.53(=92 / \mathrm{ABS}(100-40))$ by Equation 4.8 . 
However, the use of a contribution ratio larger than 1 (i.e., beyond a target) can distort the priority of advanced systems, misleading city officials to overspend a limited budget to A2-M1-S2 more than the demand while overlooking investment in other advanced systems of high-demand indicators. Thus, the maximum contribution ratio for any advanced system should be one, which is shown in the result of the contribution ratios in Table 4.7 (e.g., A2-M1-S2 and A2-M1-S3).

\subsection{Discussion}

The presented prioritization framework for advanced systems requires three basis input values, such as a target, baseline, and current development status, to function correctly. It indicates that the absence of any of these values restrains this prioritization framework from using. However, baselines and targets are essential in the performance monitoring and evaluation for managerial decision-making to achieve planned results (United States Agency for International Development, 2010). A baseline helps to understand the current progress achieved, while a target compared to current progress provides a guideline for future actions to accomplish the planned goal. According to the Information Technology Investment Baseline Management Policy (Office of Management and Budget, 2010), the agencies for IT investment management are required to provide baseline performance and proposed target performance with a description of performance measures. Thus, it concludes that the prioritization framework presented in this paper is applicable for investment-related decision-making.

The prioritization framework in this study suggests two possible approaches to determine the weights of components and indicators. One can determine the weights based on either relative importance among components (or indicators) to a smart city or different demands for components (or indicators) that were used in our demonstration. The approach based on different demands needs three basic input values, such as target, baseline, and current development status for a measure. In particular, the values for baseline and current development status are time-dependent data that should be estimated from beginning to now 
over the years. Thus, using this approach requires the capabilities (e.g., resources and managerial procedure) of a city to systematically collect and control these data. On the other hand, the approach based on relative importance compares components or indicators to each other to determine their weights. Pairwise comparison methods such as AHP and ANP are commonly used for this approach. As these methods do not require the time-dependent baseline and current development status data, this approach might be better applicable for a city in an early stage of a smart city plan. However, as these methods utilize subjective inputs in determining relative importance more or less, there should be additional considerations (e.g., use focus group or survey with large samples) to offset the subjectivity.

The priority of advanced systems as a final output assists city officials in making a transparent investment decision. However, the priority list in Table 4.8 includes the advanced systems at the same ranking, such as automated work zone information system and ramp metering that might require political judgment depending on budget limit. Suppose a city has an approved budget enough to invest in all these same ranking advanced systems. In that case, political judgment can be avoided unless there is any political intent to overturn the priority list. Political judgment takes into consideration when the approved budget for the city is not enough for both advanced systems. The choice of either advanced system relies on many various influential factors, which can include past experiences, cognitive biases, sunk outcomes, and personal (i.e., decision-maker) differences (Dietrich, 2010). Among the factors mentioned, a cognitive bias is a person's thinking pattern based on information that the person has, and the sunk outcome is a benefit or cost from the investment already made. More detail can be found in the article of Dietrich (2010). 


\section{CHAPTER 5: CONCLUSION}

\subsection{Research Summary and Contributions}

A smart city enhances its functionality to solve various urban challenges and address the different needs of citizens. The development of urban infrastructure by applying innovative technologies has been essentially vital for a city being smart. The urban road network is one of the critical infrastructures to sustain a city in operation. Thus, city officials have been making efforts to provide better public services by building advanced road systems, which are defined as the integration of modern, innovative technologies into urban roads. An efficient decision-making tool helps the city officials evaluate the current status of urban roads, identify advanced systems to improve the current status, and prioritize the advanced systems, which collectively leads to efficient investment. In particular, prioritizing advanced systems needs more delicate data analytic procedures, which motivated this thesis to develop a prioritization framework for urban road advanced systems in a smart city.

The prioritization of advanced systems first required developing a hierarchy table of indicators and measures to assess the current development status of urban roads in a smart city. A hierarchy table consists of smart city components, indicators, and measures in a hierarchy of three different levels. A text mining and synthesis study was conducted to develop a hierarchy table. For text mining, a comprehensive discovery search was conducted to collect raw documents, and the keyword networks were the basis for developing indicators and measures. The synthesis study reviewed the existing smart city indexes found from the online search and identified the smart city components applicable for urban roads. The development of the hierarchy table utilized the open-source applications (e.g., RStudio and Gephi) and analytical methods (e.g., document-term matrix and ROC) for efficient and reliable data analysis. While taking steps to maximize the reliability of data analysis, the tasks to formalize the indicators and measures were carefully performed, considering the alignment of the indicators with the existing smart city indexes and the commonality and 
conveyance of the measures. The prioritization framework presented in this thesis consists of three modules, such as a hierarchy table preparation, inputs for advanced system information, and priority of advanced systems. The method to determine the weights of smart city components and indicators was newly developed for the prioritization framework. Priority of the advanced systems was determined by the weighted cost-effectiveness values of advanced systems. All the steps in the modules of the prioritization framework were demonstrated using the data obtained from a discovery search and produced hypothetically.

As this thesis developed a hierarchy table to evaluate urban roads and prioritization framework, presenting new methods, this thesis contributes to enhancing the knowledge in infrastructure innovation for a smart city and practices in decision-making for investment in urban roads. These contributions are summarized as follows:

- A new hierarchy table of indicators and measures specific to urban roads contributes to enhancing the knowledge deficit. As another knowledge-based contribution, the procedures used to develop the indicators and measures in this paper can be developmentally applied for other individual service areas of a smart city.

- The practical use of the hierarchy table is its capability as a platform on which city planners can customize the indicators and measures considering the sizes (e.g., small, medium, and large cities) of and demands specially requested for their cities.

- The presence of the hierarchy table has the potential to promote city officials to develop a prospective decision-making practice in innovating urban roads. In general, a decision-making process to establish investment strategies begins from gathering information about current needs. The accuracy of the information is paramount for good policy-making for an investment decision. Thus, the presence of the hierarchy table has a partial contribution to developing a prospective decision-making practice in innovating urban roads.

- As the capability of prioritizing different options is core for a practical decision-making tool for 
investment, the presented framework can improve the ability of city officials to make proper investment decisions on advanced systems for urban roads.

- The weight estimation method conceived in this thesis can broaden an understanding of determining weights in performance-based decision-making problems. Thus, the presented prioritization framework is applicable for any type of urban infrastructures such as drinking and wastewaters, electricity, hospitals, and schools.

\subsection{Limitations and Recommendations}

While conducting this research, there were a few limitations encountered as with other applied research. First, there was a limited number of documents for text mining. The text mining to develop indicators and measures in a hierarchy table required documents as raw data through a discovery search. In general, the more samples, the better the quality of data analysis results. When the discovery search identified raw documents and classified them into the five smart city components, some components, such as economy and governance, were assigned to relatively smaller numbers of the documents compared to others. The reason for these differences was due to the relevance of the smart city components to urban roads. For example, the mobility component found more than 200 documents, which was the largest, as mobility is the primary concern of urban transportation. However, it should be noted that the text mining in this thesis employed the minimum threshold values varying according to the sample numbers so that the quality of the development measures for the components of small samples. As the second limitation, that the demonstration of the advanced system prioritization framework was conducted using the hypothetical data for some input values. The framework involves the input variables, such as target, baseline, and current development status values for measures as well as lifetime costs and effectiveness values for costeffectiveness analysis in the priority analysis. The data collection for these values relied on a discovery 
search in data sources open to the public, which challenged this study to obtain the data that exactly fitted into the data analysis needs.

For expanding the applicability of the hierarchy table and prioritization framework in this thesis, some future works should be considered as follows.

- The indicators and measures in a hierarchy table require continuous updates with more availability of documents related to urban roads innovation for a smart city.

- As the framework involves various mathematical functions in its procedures, the development of a computing tool can benefit city officials in implementing their smart city program systematically.

- While this thesis employed a measure-specific approach that considered the effectiveness of an advanced system pertaining to its matching measure only, other supplemental benefits from a system application can come into play for cost-effectiveness analysis. For example, city officials might consider the locality of an advanced system for a city-wide economy in its effectiveness evaluation along with the measure-specific benefit.

- Although the prioritization framework was successfully demonstrated to verify its procedures working together to generate a priority list of advanced systems, the application of the framework for a test city can provide an opportunity to evaluate its applicability into actual city-wide practice. 


\section{REFERENCES}

Albino, V., Berardi, U., \& Dangelico, R. M. (2015). Smart cities: Definitions, dimensions, performance, and initiatives. Journal of urban technology, 22(1), 3-21.

Agarwal, P. K., Gurjar, J., Agarwal, A. K., \& Birla, R. (2015). Application of artificial intelligence for development of intelligent transport system in smart cities. Journal of Traffic and Transportation Engineering, 1(1), 20-30.

American Association of State Highway and Transportation Officials. (2011). AASHTO Transportation Asset Management Guide: A Focus on Implementation. AASHTO, Washington, DC.

Bakici, T., Almirall, E., \& Wareham, J. (2013). A smart city initiative: the case of Barcelona. Journal of the knowledge economy, 4(2), 135-148.

Benchimol, J., Kazinnik, S., \& Saadon, Y. (2020). Text Mining Methodologies with R: An Application to Central Bank Texts. Bank of Israel, Research Department.

Benevolo, C., Dameri, R. P., \& D'auria, B. (2016). Smart mobility in smart city. In Empowering organizations (pp. 13-28). Springer, Cham.

Berrone, P. \& Ricart, J. E. (2019). Cities in Motion Index 2019, IESE. https://media.iese.edu/research/pdfs/ST-0509-E.pdf (accessed 05-25-2021)

Bosch, P., Jongeneel, S., Rovers, V., Neumann, M., Branislav, I., \& Huovila, A. (2017). $\begin{array}{lllll}\text { Recommendations } & \text { for } & \text { a } & \text { Smart } & \text { City }\end{array}$ http://nws.eurocities.eu/MediaShell/media/CITYkeys\%20D3.3\%20-\%20Recommendations\%20for\%20th e\%20Smart\%20City\%20Index.pdf (accessed 05-13-2021). 
Bris, A., Chee, C. H., \& Lanvin, B. (2019). Global Smart City Index 2019, IMD. https://www.imd.org/globalassets/wcc/docs/smart_city/smart_city_index_digital.pdf (accessed 05-252021)

Bruni, E., Panza, A., Sarto, L., \& Khayatian, F. (2017). Evaluation of cities' smartness by means of indicators for small and medium cities and communities: A methodology for Northern Italy. Sustainable Cities and Society, 34, 193-202.

Bujang, M. A., \& Baharum, N. (2016). Sample size guideline for correlation analysis. World Journal of Social Science Research, 3(1), 37-46.

Buzási, A., \& Csete, M. (2015). Sustainability indicators in assessing urban transport systems. Periodica Polytechnica Transportation Engineering, 43(3), 138-145.

Chakhtoura, C., \& Pojani, D. (2016). Indicator-based evaluation of sustainable transport plans: A framework for Paris and other large cities. Transport Policy, 50, 15-28.

Chen, T. M. (2010). Smart grids, smart cities need better networks. IEEE Network, 24(2), 2-3.

Chestnut, J. \& Mason, J. (2019) Indicators for Sustainable Mobility. Institute for Transportation and Development Policy, New York, NY.

Chourabi, H., Nam, T., Walker, S., Gil-Garcia, J. R., Mellouli, S., Nahon, K., Pardo, T. A., \& Scholl, H. J. (2012, January). Understanding smart cities: An integrative framework. In 2012 45th Hawaii international conference on system sciences (pp. 2289-2297). IEEE.

Curiel-Esparza, J., Mazario-Diez, J. L., Canto-Perello, J., \& Martin-Utrillas, M. (2016). Prioritization by consensus of enhancements for sustainable mobility in urban areas. Environmental Science \& Policy, 55, 248-257. 
Deveci, M., Pekaslan, D., \& Canitez, F. (2020). The assessment of smart city projects using zSlice type-2 fuzzy sets based Interval Agreement Method. Sustainable Cities and Society, 53, 101889.

Dietrich, C. (2010). Decision making: Factors that influence decision making, heuristics used, and decision outcomes. Inquiries Journal, 2(02).

Dirks, S., \& Keeling, M. (2009). A vision of smarter cities: How cities can lead the way into a prosperous and sustainable future. IBM Institute for business Value, 8.

Eremia, M., Toma, L., \& Sanduleac, M. (2017). The smart city concept in the 21st century. Procedia Engineering, 181, 12-19.

Falco, G., Viswanathan, A., Caldera, C., \& Shrobe, H. (2018). A master attack methodology for an AI-based automated attack planner for smart cities. IEEE Access, 6, 48360-48373.

Faria, R., Brito, L., Baras, K., \& Silva, J. (2017, July). Smart mobility: A survey. In 2017 International Conference on Internet of Things for the Global Community (IoTGC) (pp. 1-8). IEEE.

Figueiredo, L., Jesus, I., Machado, J. T., Ferreira, J. R., \& De Carvalho, J. M. (2001, August). Towards the development of intelligent transportation systems. In ITSC 2001. 2001 IEEE Intelligent Transportation Systems. Proceedings (Cat. No. 01TH8585) (pp. 1206-1211). IEEE.

Giffinger, R., \& Pichler-Milanović, N. (2007). Smart cities: Ranking of European medium-sized cities. Centre of Regional Science, Vienna University of Technology.

Gohar, M., Muzammal, M., \& Rahman, A. U. (2018). SMART TSS: Defining transportation system behavior using big data analytics in smart cities. Sustainable cities and society, 41, 114-119. 
Gupta, K., Zhang, W., \& Hall, R. P. (2021). Risk priorities and their co-occurrences in smart city project implementation: Evidence from India's Smart Cities Mission (SCM). Environment and Planning B: Urban Analytics and City Science, 48(4), 880-894.

Haferkamp, M., Al-Askary, M., Dorn, D., Sliwa, B., Habel, L., Schreckenberg, M., \& Wietfeld, C. (2017, June). Radio-based traffic flow detection and vehicle classification for future smart cities. In 2017 IEEE 85th Vehicular Technology Conference (VTC Spring) (pp. 1-5). IEEE.

Hall, R. E. (2000). The vision of a smart city. In Proceedings of the 2nd International Life Extension Technology Workshop, Paris, France, September 28.

Haghshenas, H., \& Vaziri, M. (2012). Urban sustainable transportation indicators for global comparison. Ecological Indicators, 15(1), 115-121.

Harrison, C., Eckman, B., Hamilton, R., Hartswick, P., Kalagnanam, J., Paraszczak, J., \& Williams, P. (2010). Foundations for smarter cities. IBM Journal of research and development, 54(4), 1-16.

Hausman, J. J., \& Buttlar, W. G. (2002). Analysis of TransTech Model 300 pavement quality indicator: laboratory and field studies for determining asphalt pavement density. Transportation research record, 1813(1), 191-200.

Jahedi, S., \& Méndez, F. (2014). On the advantages and disadvantages of subjective measures. Journal of Economic Behavior \& Organization, 98, 97-114.

Jeon, M. C. (2007). Incorporating Sustainability into Transportation Planning and Decision Making: Definitions, Performance Measures, and Evaluation (Doctoral dissertation, Georgia Institute of Technology). 
Kaparias, I., Bell, M. G. H., \& Tomassini, M. (2011). Key performance indicators for traffic management and intelligent transport systems. ISIS, 14(06).

Kasznar, A. P. P., WA Hammad, A., Najjar, M., Linhares Qualharini, E., Figueiredo, K., Soares, C. A. P., \& N Haddad, A. (2021). Multiple Dimensions of Smart Cities' Infrastructure: A Review. Buildings, 11(2), 73 .

Khademi, N., Mohaymany, A. S., \& Shahi, J. (2010). Intelligent transportation system user service selection and prioritization: hybrid model of disjunctive satisfying method and analytic network process. Transportation research record, 2189(1), 45-55.

Kim, D. B., Kim, J. J., \& Park, J. A. A Study on Priority in Application of Smart City Elements. International Journal of Innovation, Creativity and Change, 7(3), 332-347.

Kim, H., Howland, P., Park, H., \& Christianini, N. (2005). Dimension reduction in text classification with support vector machines. Journal of machine learning research, 6(1).

Knudson, D. V., \& Lindsey, C. (2014). Type I and Type II errors in correlations of various sample sizes. Comprehensive Psychology, 3, 03-CP.

Krmac, E., \& Djordjević, B. (2017). An Evaluation of Indicators of Railway Intelligent Transportation Systems using the Group Analytic Hierarchy Process. Electronics Science Technology and Application, 4(2).

Kumar, A., \& Anbanandam, R. (2020). Assessment of environmental and social sustainability performance of the freight transportation industry: An index-based approach. Transport Policy.

Kumar, R., \& Indrayan, A. (2011). Receiver operating characteristic (ROC) curve for medical researchers. Indian pediatrics, 48(4), 277-287. 
Lai, J., Qiu, J., Chen, J., Fan, H., \& Wang, K. (2015). New technology and experimental study on snow-melting heated pavement system in tunnel portal. Advances in Materials Science and Engineering, 2015.

Leobons, C. M., Campos, V. B. G., \& de Mello Bandeira, R. A. (2019). Assessing urban transportation systems resilience: a proposal of indicators. Transportation research procedia, 37, 322-329.

Li, C., Dai, Z., Liu, X., \& Sun, W. (2020). Evaluation system: Evaluation of smart city shareable framework and its applications in China. Sustainability, 12(7), 2957.

Li, R., Kido, A., \& Wang, S. (2015). Evaluation index development for intelligent transportation system in smart community based on big data. Advances in Mechanical Engineering, 7(2), 541651.

Lopez-Carreiro, I., \& Monzon, A. (2018). Evaluating sustainability and innovation of mobility patterns in Spanish cities. Analysis by size and urban typology. Sustainable Cities and Society, 38, 684696.

Magerman, T., Van Looy, B., Baesens, B., \& Debackere, K. (2011). Assessment of Latent Semantic Analysis (LSA) text mining algorithms for 20large scale mapping of patent and scientific publication documents. FBE Research Report MSI_1114.

Marsal-Llacuna, M. L., \& López-Ibáñez, M. B. (2014). Smart urban planning: designing urban land use from urban time use. Journal of urban technology, 21(1), 39-56.

Menouar, H., Guvenc, I., Akkaya, K., Uluagac, A. S., Kadri, A., \& Tuncer, A. (2017). UAVenabled intelligent transportation systems for the smart city: Applications and challenges. IEEE Communications Magazine, 55(3), 22-28. 
Mohan, A., Dubey, G., Ahmed, F., \& Sidhu, A. (2017). Smart Cities Index: A tool for Evaluating Cities, India School of Business, https://shaktifoundation.in/wp-content/uploads/2017/11/Smart-CitiesIndex.pdf (accessed 05-26-2021).

MUKUL, E., BÜYÜKÖZKAN, G., \& GÜLER, M. (2021). Prioritization of Strategic Goals for Smart City Governance with Fuzzy MCDM Techniques. Proceedings of IAC 2021 in Vienna, 1, 171.

Office of Management and Budget. (2010). Information Technology Investment Baseline Management Policy, https://www.ngoconnect.net/sites/default/files/resources/Performance $\% 20$ Monitoring $\% 20 \% 26 \% 20$ Evalua tion\%20TIPS-\%20Baselines\%20and\%20Targets.pdf (accessed 07-21-2021).

Orkphol, K., \& Yang, W. (2019). Word sense disambiguation using cosine similarity collaborates with Word2vec and WordNet. Future Internet, 11(5), 114.

Partridge, H. L. (2004). Developing a human perspective to the digital divide in the 'smart city'. In Australian library and information association biennial conference.

Pereira, G. V., Parycek, P., Falco, E., \& Kleinhans, R. (2018). Smart governance in the context of smart cities: A literature review. Information Polity, 23(2), 143-162.

Roland Berger (2019). The Smart City Breakaway Smart City Strategy Index 2019. https://www.rolandberger.com/publications/publication_pdf/roland_berger_smart_city_breakaway_1.pdf (accessed 04-24-2021)

Sas, M., Carlson, S., Kim, E., \& Quant, M. (2007). Considerations for high occupancy vehicle (HOV) to high occupancy toll (HOT) lanes conversions guidebook (No. FHWA-HOP-08-034). United States. Federal Highway Administration. 
Sharifi, A. (2019). A critical review of selected smart city assessment tools and indicator sets. Journal of cleaner production, 233, 1269-1283.

Sharifi, A. (2020). A typology of smart city assessment tools and indicator sets. Sustainable cities and society, 53, 101936.

Siksnelyte-Butkiene, I., Zavadskas, E. K., \& Streimikiene, D. (2020). Multi-criteria decisionmaking (MCDM) for the assessment of renewable energy technologies in a household: A review. Energies, 13(5), 1164.

Singhal, A. (2001). Modern information retrieval: A brief overview. IEEE Data Eng. Bull., 24(4), $35-43$.

Smart Cities Council (2014). Smart City Index Master Indicators https://smartcitiescouncil.com/system/tdf/public_resources/Smart\%20City\%20Index\%20Master\%20Indic ators.xlsx?file=1\&type=node\&id=1297\&force $($ accessed 05-26-2021).

Smiciklas, J. \& Imran, S. (2018). Global Smart Sustainable City Index 2018, International Telecommunication Union. https://www.uncclearn.org/sites/default/files/inventory/the_case_of_moscowe_18-00503_itu.pdf(accessed 05-26-2021).

Streiner, D. L., \& Cairney, J. (2007). What's under the ROC? An introduction to receiver operating characteristics curves. The Canadian Journal of Psychiatry, 52(2), 121-128.

Su, K., Li, J., \& Fu, H. (2011, September). Smart city and the applications. In 2011 international conference on electronics, communications and control (ICECC) (pp. 1028-1031). IEEE. 
Suggett, J. M., Hadayeghi, A., Mills, B., Andrey, J. C., \& Leach, G. (2006). Development of winter severity indicator models for Canadian winter road maintenance. In Annual Conference \& Exhibition of the Transportation Association of Canada, 2006. Transportation Association of Canada (TAC).

Sumalee, A., \& Ho, H. W. (2018). Smarter and more connected: Future intelligent transportation system. IATSS Research, 42(2), 67-71.

Sun, L., Zhao, H., Tu, H., \& Tian, Y. (2018). The smart road: practice and concept. Engineering, 4(4), 436-437.

Transportation Officials. (2011). AASHTO Transportation Asset Management Guide: A Focus on Implementation. AASHTO.

United States Agency for International Development. (2010). Performance Monitoring and Evaluation,https://www.ngoconnect.net/sites/default/files/resources/Performance\%20Monitoring\%20\%26 \%20Evaluation\%20TIPS-\%20Baselines\%20and\%20Targets.pdf (accessed 07-21-2021)

Urban Tide (2014). Smart Cities Maturity Model https://static1.squarespace.com/static/5527ba84e4b09a3d0e89e14d/t/55aebffce4b0f8960472ef49/1437515 772651/UT_Smart_Model_FINAL.pdf(accessed 05-25-2021).

USDOT. (2015). High-Occupancy Vehicle Lanes https://www.transportation.gov/mission/health/High-Occupancy-Vehicle-Lanes (accessed 07-06-2021).

Vasudavan, H., Mostafa, S. A., Gunasekaran, S. S., Dhillon, J. S., \& Chua, K. H. (2019, June). The contextual mapping of smart city characteristics with their dimensions through content analysis method. In 2019 7th International Conference on Smart Computing \& Communications (ICSCC) (pp. 1-5). IEEE. 
Washburn, D., Sindhu, U., Balaouras, S., Dines, R. A., Hayes, N., \& Nelson, L. E. (2009). Helping CIOs understand "smart city" initiatives. Growth, 17(2), 1-17.

Winter, J. C., Gosling, S. D., \& Potter, J. (2016). Comparing the Pearson and Spearman correlation coefficients across distributions and sample sizes: A tutorial using simulations and empirical data. Psychological methods, 21(3), 273.

Woods, E., Labastida, R. R., Citron, R., Chow, T., \& Leuschner, P. (2017). UK Smart Cities Index 2017 , Navigant. https://www.itu.int/en/ITUT/ssc/resources/Documents/Huawei_2nd_Smart_Cities_Index_2017_FINAL.pdf (accessed 05-26-2021)

Yoon, Y., Hastak, M., \& Cho, K. (2017). Preference clustering-based mediating group decisionmaking (PCM-GDM) method for infrastructure asset management. Expert Systems with Applications, 83, 206-214.

Yovanof, G. S., \& Hazapis, G. N. (2009). An architectural framework and enabling wireless technologies for digital cities \& intelligent urban environments. Wireless personal communications, 49(3), $445-463$.

Zubizarreta, I., Seravalli, A., \& Arrizabalaga, S. (2016). Smart city concept: What it is and what it should be. Journal of Urban Planning and Development, 142(1), 04015005.

Ziarmand, A. (2013, September). Smart road infrastructure. In East-West Design \& Test Symposium (EWDTS 2013) (pp. 1-5). IEEE.

23USC §150(b) (2012). United States Code, 2012 Edition, Supplement 3, Title 23 HIGHWAYSDietrich, C. (2010). Decision making: Factors that influence decision making, heuristics used, and decision outcomes. Inquiries Journal, 2(02) 